\title{
8 Bauchspeicheldruise
}

Das Pankreas besitzt trotz seiner vergleichsweise geringen Abmessungen (Länge $12-15 \mathrm{~cm}$; Gewicht $70-110 \mathrm{~g}$ ) verschiedene lebenswichtige Aufgaben: Der exokrine Anteil bildet täglich ca. 200-800 ml Bauchspeichel, der der Auflösung der Nahrungsbestandteile zu resorptionsfähigen Molekülen und der Neutralisation von Magensalzsäure dient; der endokrin aktive Teil in den Inselorganen spielt durch Ausschüttung von Insulin, Glukagon und anderen Hormonen eine zentrale Rolle in der Stoffwechselregulation. Das Pankreas wird zum bedrohlichen Krankheitsherd, wenn durch Bauchspeichel eine Selbstverdauung des Organs (Pankreatitis) bewirkt wird. Die wichtigsten Zeichen der Erkrankungen sind Schmerzen und - als Folge der Verdauungsinsuffizienz - Fettstühle.

\subsection{Embryologie, Mißbildungen}

Die Bauchspeicheldrüse ist etwa ab der 4. Embryonalwoche im Bereich des primitiven Duodenums vorhanden. Zu diesem Zeitpunkt ist sie paarig angelegt, wobei man ein ventrales und ein dorsales Pankreas unterscheiden kann (s. Abb. 7.1). Etwa um die 7. Embryonalwoche vereinigen sich beide Anlagen, indem das größere und längere dorsale Pankreas und das kleinere ventrale Pankreas sich kranial bzw. kaudal aneinander lagern (Abb. 8.1). Gleichzeitig entsteht eine Verbindung der beiden ursprünglich getrennten Ausführungsgänge, d. h. zwischen dem Ductus pancreaticus secundarius (Santorini) des Pancreas dorsale und dem Ductus pancreaticus (Wirsungi) des Pancreas ventrale, der gleichzeitig mit dem Ductus choledochus verbunden ist. Auf diese Weise entstehen der Schwanz, der Körper und der kraniale Teil des Kopfes aus dem dor-

\begin{abstract}
Abb. 8.1. Entstehung des Pankreas durch Verschmelzung der ventralen und dorsalen Anlagen (s. Abb. 7.1). Die Gangsysteme finden in unterschiedlichem Ausmaß Ausschluß; beim Pancreas divisum erscheinen sie getrennt
\end{abstract}

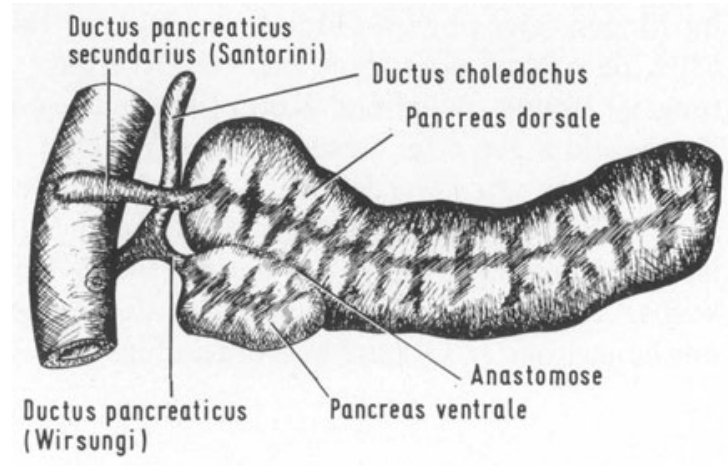


salen, der kaudale Teil des Kopfes einschließlich dem Processus uncinatus aus dem ventralen Pankreas. Im einzelnen Fall lassen sich erhebliche Abweichungen der Form, der Lage und der Gangarchitektur feststellen, die Krankheitswert besitzen können. Klinisch bedeutsam ist darüber hinaus die Tatsache, daß Schmerzen vom ursprünglichen ventralen Pankreas mehr im rechten Bauch und vom ursprünglichen dorsalen Pankreas mehr im linken Bauch empfunden werden. Aus den primitiven Ductus entwickeln sich - in beiden Anlagen gleich Gänge als seitliche Aussprossungen etwa im 3. Monat; die Langerhans-Inseln differenzieren sich um dieselbe Zeit von den Gängen des dorsalen Pankreas. Trypsinogen ist ab der 16. Woche in Azinuszellen identifiziert worden; Insulin soll noch frühzeitiger gebildet werden.

Eine seltene Anomalie ist das Pancreas anulare. Es handelt sich hier um eine abnorme Verschmelzung der beiden Bauchspeicheldrüsenanlagen, wobei das ventrale Pankreas die Pars descendens duodeni ringförmig umgibt. Klinische Erscheinungen entstehen durch die Verengung des Zwölffingerdarms sowie durch peptische Geschwüre, Pankreatitis, bzw. Blutungen. Die Manifestation kann bereits beim Neugeborenen erfolgen; häufiger beginnen Beschwerden im 5. Lebensjahrzehnt. Die Anomalie zeigt sich in der Röntgenkontrastdarstellung das Duodenums als ca. $1-3 \mathrm{~cm}$ lange Stenose, evtl. mit proximaler Erweiterung des Lumens (Abb. 8.2). Eine mögliche Fehldiagnose ist die peptische Stenose, zumal häufig Duodenalulzera zusätzlich existieren; allerdings erscheint die Engstelle weit distal. In der endoskopisch retrograden Darstellung umgibt der Ductus pancreaticus Wirsungi ringförmig von dorsal das Duodenum. Bei symptomatischen Fällen besteht die Behandlung in der Gastrojejunostomie, u. U. mit Vagotomie. Operative Maßnahmen zur Korrektur der Mißbildung werden dagegen wegen der Komplikationen nicht empfohlen.

Von einem Pancreas divisum spricht man, wenn die beiden Pankreasanlagen nicht vollständig verbunden sind und die Ausführungsgänge keinen Anschluß gewinnen. Als Folge werden der Speichel aus Schwanz, Körper sowie kranialem Kopfbereich über den Ductus pancreaticus secundarius Santorini und der Speichel aus Processus uncinatus sowie kaudalem Kopfbereich über den Ductus pancreaticus Wirsungi getrennt in das Duodenum geleitet (Abb. 8.3). Die relativ kleine Einmündung des Ductus Santorini bei der Papilla minor soll infolge eines vermehrten Widerstands das Auftreten von Bauchspeicheldrüsenentzündungen begünstigen.

Ektopisches Bauchspeicheldrüsengewebe wird bei etwa 3\% der Bevölkerung im Magen oder oberen Dünndarm, seltener in der Leber, der Gallenblase, der Milz, dem Netz oder dem Meckel-Divertikel gefunden. Die klinische Bedeutung ist gering. Mögliche Komplikationen sind Entzündungen (Pankreatitis), Zystenbildungen oder Geschwülste.

Pankreaszysten werden als Fehlbildung allein oder in der Kombination mit Zysten in anderen Organen (Nieren, Leber, Kleinhirn) beobachtet. Der Inhalt ist enzymarm. Die Wand besteht aus wenig Bindegewebe sowie einschichtigem kubischem Epithel. Beschwerden werden insbesondere durch die Verdrängung der benachbarten Organe hervorgerufen. 


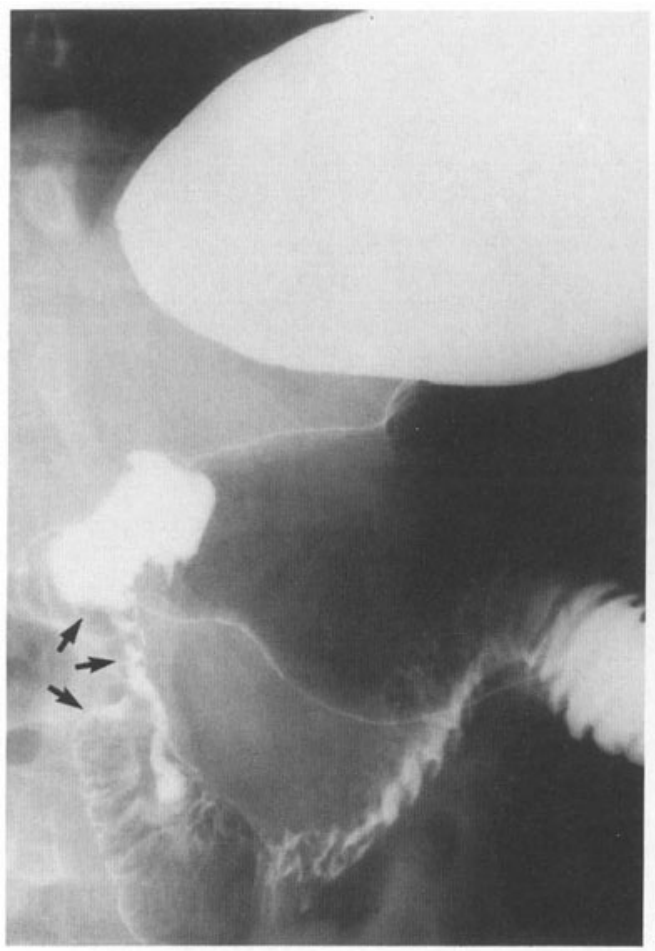

Abb. 8.2

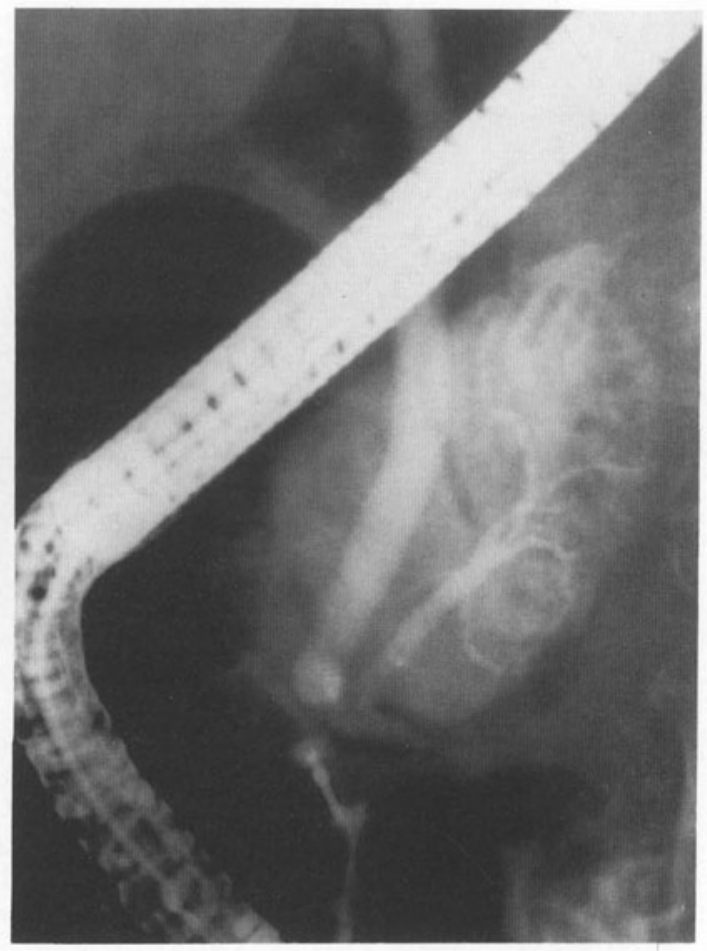

Abb. 8.3

Abb. 8.2. Pancreas anulare. Die Pfeile markieren die Impression des Duodenum descendens durch das ventrale Pankreas. - Es handelt sich hier um die zufällige Entdeckung bei der Röntgenkontrastdarstellung des Zwölffingerdarms. Der Patient war trotz der hochgradigen Stenose symptomfrei

Abb. 8.3. Pancreas divisum. Dargestellt ist hier die ehemals ventrale Pankreasanlage, die vom Ductus pancreaticus Wirsungi drainiert wird und zusammen mit dem Ductus choledochus bei der Papilla Vateri einmündet (s. auch Abb. 8.1)

\subsection{Anatomie}

Die Bauchspeicheldrüse erscheint länglich zwischen dem Duodenalbogen und der Milz ausgestreckt. Das rechte Ende wird als Kopf bezeichnet; hier ist das Organ rundlich und weist nach kaudal den hakenförmigen Processus uncinatus auf, der von der Arteria und Vena mesenterica superior durchzogen wird. Ventral verlaufen Pylorus und Colon transversum; der Ductus choledochus zieht entweder in einer Rinne zwischen Drüse und Duodenum oder durch die Drüse selbst (Abb. 8.4). Dorsal berührt der Kopf die große Hohlvene, die linke Nierenvene und die Aorta. Der Körper bildet die nach links anschließende schlanke Fortsetzung. Am kranialen Rand verläuft die A. lienalis, die V. lienalis findet sich entlang der dorsalen Oberfläche. In der Sonographie läßt sie sich gut darstellen und dient als Markierung der Pankreasloge. Das Ende ist der schmal 


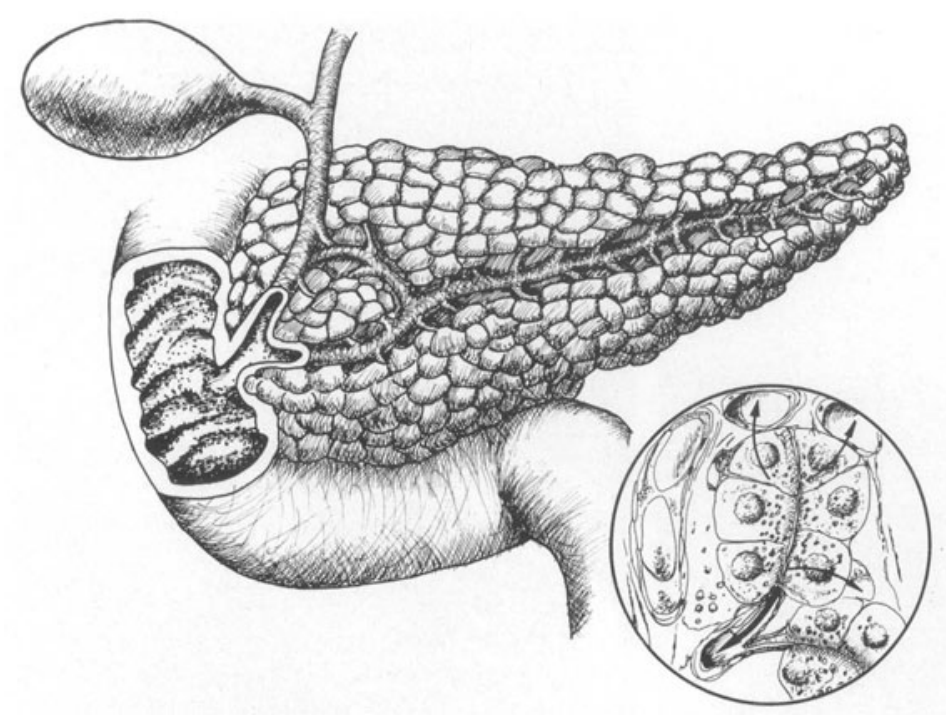

Abb. 8.4. Anatomie des Pankreas. In dieser Schemazeichnung wird die Lagebeziehung der großen Gänge zum Ductus choledochus sowie die Situation am Zwölffingerdarm verdeutlicht. Rechts unten erscheint ein mikroskopisches Bild der Azini. Sie können ein enzymreiches Sekret in den betreffenden Gang und - gering - in die umgebenden Gewebe ausschütten, das dann schließlich im Blut erscheint. Gangepithelien bilden ein wasser- und elektrolytreiches Sekret. Zum Teil sind sie auch innerhalb von Azini zu finden (,zentroazinär"). (Nach [5])

ausgezogene Schwanz, der in der Nähe der Milz und der linken Niere gelegen ist. Die Lage des Pankreas ist retroperitoneal. Die ventrale Fläche ist mit Peritoneum parietale sowie - längs nahe der Unterkante von Korpus und Schwanz und über die Mitte des Kopfes ziehend - mit Mesocolon transversum bedeckt. Zwischen der Drüse und dem Magen liegt die Bursa omentalis. Diese Gegebenheiten sind für die Ausbreitung der akuten Entzündungen von Bedeutung (s. 8.5).

Die Ausführungsgänge weisen große Unterschiede auf, die sich durch die Entstehung aus 2 Anlagen erklären lassen (s. 8.1). Bei der überwiegenden Zahl der Bevölkerung wird der Bauchspeichel aus dem Ductus pancreaticus secundarius Santorini über den Ductus pancreaticus Wirsungi zur Papilla major geleitet. Dort münden Pankreasgang und Gallengang gemeinsam in das Duodenum. Bei etwa 20\% mündet ein akzessorischer Pankreasgang bei der Papilla minor in den Zwölffingerdarm; in den meisten Fällen wird dieser dagegen vom Ductus Wirsungi drainiert. Der Durchmesser des Pankreasgangs beträgt im Kopf ca. 3,5 mm, im Korpus ca. $3 \mathrm{~mm}$ und im Schwanz ca. 2,5 mm. Mit dem Alter wird eine Zunahme des Lumens beobachtet. Der Pankreashauptgang erhält Zuflüsse von 15-30 Nebengängen (1. Ordnung), die sich in Ductuli (2. Ordnung) und Canaliculi (3. Ordnung) aufzweigen. Besondere Bedeutung erhält das Gangbild, seitdem auf endoskopisch retrogradem Weg eine Röntgenkontrastdarstellung (ERP) möglich ist (s. 1.5.3).

Etwa 86 Vol.-\% der Bauchspeicheldrüse sind exokrine Drüsenzellen; die Inseln machen lediglich 2 Vol.-\% aus. Der Rest baut sich aus Bindegewebe, Gefä- 
ßen oder Nerven auf, die die Drüse reich durchsetzen und die Struktur mit Lappen und Läppchen mitgestalten. Die kleinste Einheit sind Azini, die aus den pyramidenförmigen Azinuszellen bestehen. Sie stellen in bemerkenswerter Weise die exkretorischen Pankreasenzyme her und geben diese an ihrer apikalen Seite in das Gangsystem. Die breite Basis der Azinuszellen grenzt an die Basalmembran, die einen engen Kontakt zu feinen Gefäßen und Nerven herstellt (s. Abb. 8.4). Auf dem Wege ist auch der Übertritt von Enzymen in das Blut denkbar; dieser Sachverhalt besitzt eine große Bedeutung für die Diagnostik. An die Azini finden Ausführungsgänge mit kubischem oder zylindrischem Epithel in charakteristischer ,zentroazinärer“ Lage Anschluß. Diese Zellen sind zur Sekretion von Wasser und Elektrolyten befähigt. Die Gangepithelzellen nehmen etwa 4 Vol.-\% der Bauspeicheldrüse ein. In den Inseln lassen sich verschiedene Zellen unterscheiden. Etwa 75\% sind B-Zellen, die Insulin sezernieren; A-Zellen sind vorwiegend an der Peripherie lokalisiert; sie nehmen etwa $20 \%$ ein und sind zur Herstellung von Glukagon spezialisiert. D-Zellen sollen Somatostatin an die umgebenden Gewebe, d.h. parakrin, abgeben. Weitere Zellelemente sollen zur Bildung von vasoaktivem intestinalem Polypeptid (VIP) und pankreatischem Polypeptid (PP) ausgestattet sein.

Die Blutversorgung erfolgt aus dem Truncus coeliacus und der A. mesenterica superior. Hierbei gewinnen die Gefäße reichen und dichten Anschluß an die Drüsenzellen. Bemerkenswert sind Gefäßverbindungen zwischen Pankreasinseln und benachbarten Azini, die ein ,,insuloazinäres Pfortadersystem“ herstellen und möglicherweise eine regulierende Funktion ermöglichen. Der Blutabfluß geschieht über die V. lienalis, die V. mesenterica superior oder über Pfortaderäste. Lymphbahnen folgen den Gefäßen und sammeln sich schließlich in den zöliakalen Lymphknoten.

Das Pankreas wird reichlich mit vegetativen Nerven versorgt, wobei sowohl Äste des N. vagus als auch des N. sympathicus beteiligt sind. Nach der Umschaltung in unterlobulären Ganglien werden vom $\mathrm{N}$. vagus sekretorische Reize auf die Drüsenzellen übertragen. Sensorische Fasern verlaufen mit dem Sympathikus und erreichen das Rückenmark in der Höhe von $\mathrm{Th}_{5}-\mathrm{Th}_{9}$.

\subsection{Physiologie}

Das Pankreas sezerniert täglich etwa 200-800 ml Bauchspeichel. Es gewinnt damit eine zentrale Stellung bei der luminalen Verdauung. Der Beitrag des Mundspeichels und das Magensaftes, in denen u. a. Amylase bzw. Pepsin enthalten sind, ist im Vergleich geringer. Dies wird beim Ausfall der jeweiligen Organfunktion deutlich: Allein die exkretorische Pankreasinsuffizienz erfordert eine Substitutionsbehandlung.

Der Bauchspeichel enthält Sekret von den Azinuszellen und von den Gangepithelzellen, die teilweise im Zentrum der Azini gelegen sind (,zentroazinäre Zellen“ s. 8.2). Die Azinuszellen bilden einen protein- bzw. enzymreichen, elektrolythaltigen Saft. Er besteht u. a. aus Lipase, $\alpha$-Amylase, 4 (Pro-)Carboxypeptidasen, 3 Trypsinogenen, Chymotrypsinogenen, 2 Proelastasen, 2 Colipasen so- 
wie Prophospholipase $A_{2}$. Diese Proteine werden im endoplasmatischen Retikulum und anschließend im Golgi-Apparat der Azinuszellen hergestellt und in Zymogengranula gespeichert. Nach einem Reiz - z. B. Pankreozymin - werden sie mittels Exozytose in das Lumen abgegeben. Gleichzeitig erfolgt eine Freisetzung von Flüssigkeit. Die Aktivierung der Enzyme geschieht nach Übertritt in den Dünndarm durch Trypsin, das zuvor von dem Bürstensaumferment Enterokinase in die aktive Form überführt werden muß. Gangepithelzellen schütten ein wäßriges Sekret aus, dessen wichtigster Bestandteil Bikarbonat ist. Weiterhin sind - als wichtigstes Kation - Natrium, sowie Kalium, Kalzium und Magnesium enthalten; die Konzentration der Kationen entspricht derjenigen der beiden Anionen Bikarbonat und Chlorid. Mit zunehmender Sekretionsrate steigt die Abgabe von Bikarbonat und fällt die Ausschüttung von Chlorid; die Konzentration der Kationen wird gleichzeitig nicht wesentlich beeinflußt. Die Leber bildet mit der gallensäureunabhängigen Fraktion ein Sekret, das gleich zusammengesetzt ist und ähnlichen Regulationsmechanismen folgt. Bei Überlegungen zur Bikarbonat- und Wassersekretion ist deshalb gegebenenfalls der Beitrag der Galle zu berücksichtigen.

Die Regulation der exokrinen Pankreassekretion hat in den letzten Jahren das Interesse einer Vielzahl von Forschern gefunden. Auch wenn ein endgültiges Verständnis der verschiedenen Mechanismen fehlt, so lassen sich doch einige Grundprinzipien angeben. Die wichtigsten Sekretionsreize gehen offenbar vom N. vagus (Azetylcholin) sowie von den Hormonen Sekretin und Pankreozymin/Cholezystokinin aus. Sowohl die Reizung des N. vagus als auch Pankreozymin führen zur Bildung eines eiweißreichen Sekretes durch die Azinuszellen (ekbole Wirkung); Sekretin führt dagegen zur Ausschüttung eines wäßrigen, bikarbonathaltigen Saftes durch die zentroazinären Zellen bzw. die Pankreasgangepithelien (hydrokinetische Wirkung). Daneben existieren weitere Mediatoren, deren Effekte nur zum Teil gesichert sind. So besitzen Gastrin, Bombesin, Chymodenin, Histamin, Insulin, Somatomedin, Motilin und Neurotensin stimulierende Wirkungen bei Azinuszellen; hemmend sind bei allen exokrinen Drüsenzellen Somatostatin, pankreatisches Polypeptid, Enkephalin und z. T. Glukagon. Im Zusammenhang mit Gangepithelzellen konnten peptiderge Nerven mit vasoaktivem intestinalem Polypeptid (VIP) identifiziert werden, die wahrscheinlich in ähnlicher Weise wie Sekretin angreifen. Der N. sympathicus soll durch Verminderung der Blutzufuhr die Sekretion hemmen.

Bereits im Nüchternzustand findet man eine geringe, mit dem interdigestiven myoelektrischen Komplex rhythmisch alle 40-120 min auftretende Sekretion von Enzymen und Bikarbonat; vergleicht man mit dem maximalen Ausstoß, so beträgt die für etwa 10-15 min nachweisbare Sekretion ca. 20\%. Im Zusammenhang mit einer Mahlzeit führen verschiedene Reize zu einer Vermehrung bzw. Verminderung der Speichelbildung. Während der zephalen Phase sind es der Anblick, der Geruch oder der Geschmack, die über den N. vagus sekretorisch wirken. Beim Eintritt der Speisen in den Magen wird durch die Dehnung der Wand wahrscheinlich auf dem Weg über den N. vagus sowie durch den Kontakt mit der Wand des Antrums über eine Freisetzung von Gastrin und evtl. Bombesin die Saftbildung angeregt (gastrische Phase). Mit dem Übertritt in das Duodenum beginnt die intestinale Phase der Pankreassekretion. Das 
Ausmaß des Bauchspeichelflusses wird zunächst von der Geschwindigkeit der Magenentleerung bestimmt. Fette treten vergleichsweise langsamer als Kohlenhydrate oder Eiweiße in den Zwölffingerdarm über. Vermittelnd wirken hierbei sowohl von der Duodenalschleimhaut ausgehende Nerven (N. vagus) als auch Hormone. Die Effekte der verschiedenen Nahrungsbestandteile sind hierbei unterschiedlich. So stimulieren große Proteinmoleküle oder intakte Fettmoleküle nicht; langkettige Fettsäuren, Peptide, Phenylalanin oder Tryptophan bewirken dagegen einen starken Sekretionsreiz. Neben der Zusammensetzung der Speisen spielt die Größe der Kontaktfläche eine wichtige Rolle. Schließlich sei der enthaltene (Salz-)Säuregehalt als weitere Determinante der Sekretion erwähnt: Steigt der duodenale pH-Wert über 4,5, so kommt es zu einer Freisetzung von Sekretin und damit zu einer Ausschüttung von bikarbonathaltigem Saft.

Der Bauchspeichel enthält neben Elektrolyten eine Reihe von Proteinen bzw. Enzymen. Tabelle 8.1 gibt einen Überblick über die in den Azinuszellen gebildeten Verdauungsenzyme und deren Funktionen. Die verschiedenen Proteasen katalysieren nach ihrer Aktivierung durch Enterokinase bzw. Trypsin (s. oben) die Aufspaltung bestimmter, innerhalb des Moleküls gelegener (Endopeptidasen) und am Ende des Moleküls gelegener Peptidbindungen (Exopeptidasen). Es entstehen auf diese Weise resorptionsfähige Oligopeptide und Aminosäuren. Kohlenhydrate werden an $\alpha$-1,4-glykosidischen Bindungen in der Gegenwart von $\alpha$-Amylase gespalten; auch hierbei entstehen resorptionsfähige

Tabelle 8.1. Verdauungsenzyme im menschlichen Bauchspeichel

\begin{tabular}{|c|c|c|}
\hline $\begin{array}{l}\text { Enzym } \\
\text { (aktive Form) }\end{array}$ & Molekulargewicht & Funktion \\
\hline Trypsin & $\begin{array}{c}23400,25000 \\
\text { (Trypsinogene) }\end{array}$ & $\begin{array}{l}\text { Endopeptidase: Spaltung von Arginin- } \\
\text { und Lysinbindungen }\end{array}$ \\
\hline Chymotrypsin & $\begin{array}{l}24000,27000 \\
\text { (Chymotrypsinogene) }\end{array}$ & $\begin{array}{l}\text { Endopeptidase: Spaltung von Tyrosin-, } \\
\text { Tryptophan- und Phenylalaninbindungen }\end{array}$ \\
\hline Elastase & 25000,29300 & $\begin{array}{l}\text { Endopeptidase: Spaltung von Bindungen } \\
\text { bei aliphatischen Aminosäuren }\end{array}$ \\
\hline Carboxypeptidase A & $\begin{array}{l}34000,46000 \\
\text { (Proenzyme) }\end{array}$ & $\begin{array}{l}\text { Exopeptidase: Spaltung von endständigen } \\
\text { Peptidbindungen }\end{array}$ \\
\hline Carboxypeptidase B & 30000,47000 & $\begin{array}{l}\text { Exopeptidase: Spaltung von endständigen } \\
\text { Peptidbindungen }\end{array}$ \\
\hline Phospholipase $\mathrm{A}_{2}$ & 14000 & $\begin{array}{l}\text { Hydrolyse von Lezithin zu } \\
\text { Lysolezithin etc. }\end{array}$ \\
\hline Lipase & 48000 & $\begin{array}{l}\text { Hydrolyse der Triglyzeride } \\
\left(\mathrm{C}_{1} \text { - und } \mathrm{C}_{3} \text {-Esterbindungen }\right)\end{array}$ \\
\hline Colipase & 9900 & Kofaktor der Lipase \\
\hline $\begin{array}{l}\text { Carboxylester- } \\
\text { hydrolase }\end{array}$ & 100000 & $\begin{array}{l}\text { Hydrolyse von Esterbindungen } \\
\text { z. B. Fluoresceindilaurat }\end{array}$ \\
\hline$\alpha$-Amylase & 53000 & Hydrolyse von Stärke \\
\hline Ribonuklease & 15000 & $\begin{array}{l}\text { Spaltung von Ribonukleinsäure } \\
\text { (Phosphatesterbindung) }\end{array}$ \\
\hline Desoxyribonuklease & 38000 & $\begin{array}{l}\text { Spaltung von Desoxyribonukleinsäure } \\
\text { (Phosphatesterbindung) }\end{array}$ \\
\hline
\end{tabular}


Oligosaccharide und Monosaccharide. Für die volle Enzymaktivität ist die Gegenwart von Chloridionen nötig. Die Aufspaltung der Fette bedeutet insofern ein Problem, als das Substrat für die Enzymwirkung wasserunlöslich ist, Enzyme jedoch nur im wäßrigen Milieu aktiv sind. Durch die Mitwirkung von Galle werden deshalb Lipide in kleine Tröpfchen aufgelöst und mit einer hydrophilen Oberfläche aus Gallensäuren, Fettsäuren oder Lezithin überzogen. An dieser Grenzfläche können Phospholipase $\mathrm{A}_{2}$ und Carboxylesterhydrolase angreifen. Für die Wirkung der Lipase ist die Gegenwart von Colipase nötig.

Innerhalb von $24 \mathrm{~h}$ ist das Pankreas befähigt, etwa 15-20 g Enzymprotein zu bilden und mit dem Bauchspeichel abzugeben. Es übertrifft damit die Leistungsfähigkeit anderer sekretorischer Drüsen. Für die normale Verdauungsfunktion ist nur eine Teilmenge dieser Enzyme nötig. Dies zeigt sich am besten beim Wegfall eines Teiles der Drüse infolge chronischer Entzündung oder Resektion: Eine Funktionseinschränkung ist erst meßbar, wenn mehr als $90 \%$ der exokrinen Drüsenanteile ausgefallen sind.

Besonderes Interesse hat in den letzten Jahren die Frage nach der Anpassung der Speichelzusammensetzung an die Kostform gefunden. Aus verschiedenen Beobachtungen bei Tieren kann geschlossen werden, daß Adaptationsvorgänge existieren. Darüber hinaus werden Enzyme unabhängig voneinander ausgeschüttet, z. B. Amylase und Chymotrypsin. Ein gültiges Verständnis dieser Phänomene steht noch aus.

Neben Enzymen finden sich in einem geringen Prozentsatz $(1-3 \%)$ andere Eiweißkörper im Bauchspeichel. Erwähnt werden sollen Immunglobuline, Albumin, Laktoferrin und karzinoembryonales Antigen. Zum Teil sind Konzentrationsänderungen im Zusammenhang mit Erkrankungen beobachtet worden.

\subsection{Klinisch-chemische Diagnostik einschließlich Funktionstests}

Für die Beurteilung der Bauchspeicheldrüse gibt es neben den bildgebenden Verfahren - Sonographie, Computertomographie, endoskopische retrograde Pankreatikographie (ERP), Angiographie etc. - verschiedene klinisch-chemische Tests und Funktionsprüfungen. Sie sollen hier kurz dargestellt werden.

\subsubsection{Aktivitätsbestimmung von Pankreasenzymen in Blut, Urin und Erguissen}

Die Bauchspeicheldrüse enthält reichlich Enzyme, die sich bereits beim Gesunden in den verschiedenen Körperflüssigkeiten nachweisen lassen. Diagnostischen Wert besitzen vor allem $\alpha$-Amylase und Lipase.

\section{$\alpha$-Amylase}

$\alpha$-Amylase wird von der Bauchspeicheldrüse sowie den Mundspeicheldrüsen gebildet und sezerniert. Hierbei gelangen geringe Mengen in das Interstitium 
und schließlich in das Blut. Der Abbau erfolgt dann durch die Leber und durch die Nieren, wo der größere Teil mit dem Urin ausgeschieden wird. Die biologische Halbwertszeit beträgt etwa $2-3 \mathrm{~h}$.

Für die Bestimmung der $\alpha$-Amylase in den Körperflüssigkeiten gibt es verschiedene Verfahren. Sie erfassen entweder den Verbrauch von Substrat oder die Bildung von Abbauprodukten. Hier sind in den letzten Jahren synthetische Substrate aus Maltosiden eingeführt worden, die im zusammengesetzten optischen Test rasche und gut reproduzierbare Messungen erlauben. Man erhält sie als fertige Reagenziensätze im Handel. ( $\alpha$-Amylase PNP Boehringer; Tostomar $\alpha$-Amylase, Behringwerke; Monoamyl neu Biomed.) Bei den chromogenen Methoden dienen Stärkepolymerisate, in die Farbstoffe chemisch eingeschlossen wurden, als Substrat. Die Enzymwirkung wird anhand der Farbstofffreisetzung erfaßbar (Amylochrome Roche). Auf einem ähnlichen Prinzip beruht der Amylasenachweis im Urin mittels Teststreifen (Rapignost Amylase, Behringwerke). Durch einen Inhibitor aus Weizen, der gegenüber Pankreasamylase wirksam ist, läßt sich eine getrennte Bestimmung der beiden Enzyme erreichen (Phadebas Isoamylasen, Pharmacia).

Erhöhte Aktivitäten der $\alpha$-Amylase werden hauptsächlich bei Entzündungen gefunden. Durch Zellschädigung treten vermehrt Enzyme in die Umgebung aus und werden mit der Lymphe bzw. dem Blut transportiert oder sammeln sich in Ergüssen (Bauchhöhle, linksseitige Pleurahöhle) an. Hohe Enzymaktivitäten werden auch im Inhalt von Pankreaspseudozysten gemessen.

Die größte praktische Bedeutung besitzen Amylasebestimmungen im Serum. Bei der Bewertung der Resultate ist zu bedenken, daß wegen der raschen Abbaurate (s. oben) Aktivitätsanstiege u. U. nur kurzzeitig erfaßbar sind; darüber hinaus gibt es extrapankreatische Erkrankungen, bei denen die Amylaseaktivität erhöht gefunden wird. Eine Übersicht möglicher Ursachen der Hyperamylasämie folgt:

\section{Ursachen der Hyperamylasämie}

- Pankreaserkrankungen: Entzündungen, Verletzungen, Geschwülste

- Speicheldrüsenerkrankungen: Entzündungen, Verletzungen, Geschwülste

- Niereninsuffizienz

- Makroamylasämie

- Gallenwegserkrankungen

- Diverse Baucherkrankungen: perforiertes Ulcus duodeni, Mesenterialinfarkt, Syndrom der zuführenden Schlinge, Peritonitis, akute Appendizitis, Ileus, rupturierte ektopische Schwangerschaft

- Verbrennungen, Schock

- Postoperative Hyperamylasämie

- Diabetische Ketoazidose

- Geschwülste (bes. Lungen, Dickdarm, Eierstöcke)

Die jeweiligen Mechanismen sind nur z. T. bekannt. Ungeklärt sind beispielsweise die Aktivitätsanstiege bei den diversen Baucherkrankungen, die im einzelnen Fall zu diagnostischen Schwierigkeiten führen; möglich ist hier eine evtl. begleitende Pankreatitis. Hyperamylasämien im Rahmen von Geschwulstleiden werden auf eine eigene Enzymsynthese der Tumoren zurückgeführt. In 
der Mehrzahl der Patienten soll es sich biochemisch um Speichelamylase handeln.

In den letzten Jahren hat der Beitrag der Nieren zur Elimination der Amylase vermehrt Beachtung gefunden. Bei der Makroamylasämie erscheinen im Blut Amylasemoleküle, die von den Nieren nicht abgebaut bzw. ausgeschieden werden können. Entsprechend sind die Enzymaktivitäten im Serum erhöht und gleichzeitig im Harn innerhalb des Normbereichs. Für eine gültige Diagnose dieser harmlosen Anomalie (Häufigkeit ca. 1\%) ist eine chromatographische Analyse nötig. - Schwere akute Bauchspeicheldrüsenentzündungen führen zu einer Nierenfunktionsstörung. Hierbei wird die tubuläre Rückresorption der Pankreasamylase gehemmt und die Clearance bis auf $40 \%$ gesteigert. Erfaßbar ist dieses Phänomen durch den Vergleich mit der Kreatininclearance, die weniger betroffen wird. In der Praxis wird das Verhältnis Amylaseclearance/Kreatininclearance nur selten bewertet.

Erniedrigte Amylaseaktivitäten im Serum werden im Rahmen von chronischen Bauchspeicheldrüsenerkrankungen als Folge der verminderten Azinuszellzahl beobachtet. Allerdings zeigt sich selbst bei Zugrundelegung der pankreasspezifischen Amylase eine breite Überschneidung der Meßwerte mit denen der Pankreasgesunden. Die diagnostische Bedeutung ist deshalb gering.

\section{Lipase}

Lipase wird in ähnlicher Weise wie Amylase aus den Azinuszellen des Pankreas in das Blut abgegeben. Der Abbau erfolgt vorwiegend in den Nieren; eine Ausscheidung mit dem Urin wird jedoch nicht beobachtet. Vermehrte Enzymaktivitäten sind in Analogie zur Amylase bei Bauchspeicheldrüsenerkrankungen, Nierenerkrankungen sowie bei schweren Baucherkrankungen zu finden. Störungen durch Speicheldrüsenenzyme sind nicht zu erwarten. Im Vergleich ist die Lipaseaktivität bei akuten Bauchspeicheldrüsenentzündungen häufiger pathologisch [4]. Störungen der Messungen können von unspezifischen Esterasen oder von Lipoproteinlipasen, die durch Heparingabe in das Blut freigesetzt werden, ausgehen.

Messungen der Lipase sind erschwert, weil das Substrat - langkettige Triglyzeride (Olivenöl, Triolein) - wasserunlöslich ist und erst durch Lösungsvermittler in einen geeigneten, im wäßrigen Medium reaktionsfähigen Zustand gebracht werden muß. Unter der Einwirkung von Lipase werden Fettsäuren und Diglyzeride abgespalten. Bei den titrimetrischen Verfahren werden die in der Zeiteinheit freigesetzten sauren Valenzen der Fettsäuren bewertet. Methodisch einfacher durchführbar sind turbidimetrische Verfahren, bei denen mittels Photometrie die Trübungsabnahme des Substrates ausgewertet wird. Durch den Gehalt an Colipase wird die Spezifität für Pankreaslipase verbessert. (Im Handel: Monotest Lipase, Boehringer.) Schließlich gibt es einen immunologischen Lipasetest, der die Konzentration von Lipaseprotein erfaßt (Enzygnost Lipase, Behringwerke). 


\subsubsection{Funktionstests des exokrinen Pankreas}

Die Funktion des exokrinen Pankreas besteht in der Sekretion des enzymprotein- und elektrolythaltigen Bauchspeichels. Direkte Testverfahren bewerten den Ausstoß der verschiedenen Bestandteile nach einem definierten Reiz. Hierbei werden entweder Hormone (Sekretin-Pankreozymin-Test) oder eine Testmahlzeit (z. B. Lundh-Test) verwendet. Wegen des relativ großen Aufwandes (Duodenalsonde bzw. Pankreasintubation) sind diese Methoden nicht als Suchreaktionen geeignet. Indirekte Testverfahren werden ohne Sonden durchgeführt. Durch sie werden die verminderte Verdauung definierter Substanzen (NBTPABA; Fluoreszeindilaurat) oder die geringere Ausscheidung der exkretorischen Pankreasenzyme mit dem Stuhl (Chymotrypsin) ausgewertet. Wegen der großen Funktionsreserve der Bauchspeicheldrüse sind pathologische Resultate erst bei fortgeschrittenen Erkrankungen, bei denen die Enzymabgabe auf weniger als 10\% eingeschränkt ist, zu erwarten. Die direkten Funktionstests sind spezifischer und den indirekten Verfahren überlegen. Letztere werden vor allem als Suchverfahren eingesetzt. Im Vergleich ermöglicht der Sekretin-Pankreozymin-Test die empfindlichste Prüfung des exokrinen Pankreas.

\section{Sekretin-Pankreozymin-Test}

Beim Sekretin-Pankreozymin-Test wird der Bauchspeichel mittels Duodenalsonde nach Injektion von Sekretin und Sekretin/Pankreozymin gewonnen und untersucht. Bewertet werden in der Sekretinphase der Ausstoß an Bikarbonat und Wasser sowie in der Sekretin-/Pankreozymin-Phase die Freisetzung von Enzymen (Amylase, Lipase, Trypsin, Chymotrypsin). Leider existieren für die Durchführung keine verbindlichen Richtlinien. So gibt es Unterschiede bei den Hormonen bzw. deren Dosierungen und der Dauer der Sammelperioden. Darüber hinaus ist der Test durch verschiedene Fehlermöglichkeiten belastet: Sammelfehler oder Zufluß von Magensekret, die eine verminderte Pankreassekretion vortäuschen; Verlust der Enzymaktivitäten infolge unsachgemäßer Handhabung der Saftproben nach dem Test (Auffangen in gekühlten Behältern, ggf. Einfrieren mit Glyzerin 87\% zu gleichen Teilen). Eine ausführliche Diskussion über Indikationen, praktische Durchführung und Auswertungen wurde kürzlich veröffentlicht [7]. In der Regel erfolgt nach einer Vorperiode der Test über $2 \mathrm{~h}$. Eine Korrektur von etwaigen Sammelfehlern durch Instillation eines Markers (Polyäthylenglykol) wird bei wissenschaftlichen Fragestellungen empfohlen. Der Test sollte bei Patienten mit Pankreatitis nur nach Abklingen der akuten Erscheinungen, $d$. h. frühestens nach 2-3 Wochen, erfolgen.

Bei einer leichten Pankreasinsuffizienz findet man eine Verminderung einzelner Enzyme; der Ausstoß von Bikarbonat und Wasser ist dagegen im Normbereich. Mittelschwere Erkrankungen zeigen eine erniedrigte Sekretion der Enzyme; die Bikarbonat- und Volumenraten sind im unteren Normbereich. Eine schwere Pankreasinsuffizienz geht mit einer Verminderung aller Parameter einher. 


\section{Chymotrypsinausscheidung mit dem Stuhl}

Ein Teil des pankreatischen Chymotrypsins wird mit dem Stuhl unverändert ausgeschieden. Bei einer Insuffizienz des exokrinen Pankreas nimmt die Enzymaktivität im Stuhl ab. Da Chymotrypsin gebunden erscheint, ist für die Messung die vorherige Freisetzung erforderlich. Bewertet wird der Enzymgehalt in $1 \mathrm{~g}$ Stuhl; eine Homogenisierung bzw. Ermittlung des Stuhlgewichts ist nicht erforderlich. In der Regel genügt ca. $1 \mathrm{~g}$ Stuhl. Durch einen neueren käuflichen Reagenziensatz lassen sich Bestimmungen mit dem Photometer leicht routinemäßig ausführen (Monotest Chymotrypsin/Solvens; Fa. Boehringer).

Erfaßbar sind mit diesem Verfahren fortgeschrittene Erkrankungen; der prozentuale Anteil der richtig erkannten Fälle wird in verschiedenen Studien mit etwa $90 \%$ angegeben. Leichtere Pankreasinsuffizienzen werden dagegen etwa zur Hälfte nicht entdeckt. Falsch-erniedrigte Ausscheidungsraten findet man bei Magenresektionen (Billroth-II-Operationen), Sprue, komplettem Verschlußikterus oder Mangelernährung mit eingeschränkter Proteinsynthese. Durch eine Substitutionsbehandlung mit Pankreasenzymen kann eine normale Sekretion vorgetäuscht werden; daher müssen diese 4 Tage vor der Stuhluntersuchung abgesetzt werden. Bei 10-15\% der Pankreasgesunden muß mit einem falsch-pathologischen Ergebnis gerechnet werden.

\section{Fluoreszeindilaurattest}

Fluoreszeindilaurat wird in Gegenwart von pankreatischer Carboxylesterhydrolase in resorptionsfähiges Fluoreszein gespalten. Als Folge einer exkretorischen Pankreasinsuffizienz entsteht nach oraler Gabe von Fluoreszeindilaurat weniger freies Fluoreszein; entsprechend nimmt die Ausscheidung mit dem Urin ab. Beim Fluoreszeindilaurattest wird sowohl die Fluoreszeinausscheidung nach Gabe des Dilaurylesters als auch nach Gabe von freiem Fluoreszein gemessen und verglichen. Die Untersuchung muß an 2 Tagen durchgeführt werden. Bei Verwendung der handelsüblichen Testpackung (PankreolaurylTest Temmler) sammeln die Patienten für $10 \mathrm{~h}$ nach der Einnahme der Testsubstanzen den Urin. Für die Messungen sind im Routinelabor vorhandene Geräte (Photometer etc.) nötig. Setzt man die Fluoreszeinausscheidung nach Gabe von Fluoreszein (Kontrollversuch) mit $100 \%$ an, so werden nach Fluoreszeindilaurat beim Gesunden mehr als 30\% des Metaboliten im Urin gefunden. Als sicher pathologisch gilt ein Wert von unter 20\%. Fehler entstehen durch die unzureichende Harnsammlung bzw. die zu geringe Harnproduktion (mindestens $600 \mathrm{ml}$ ). Die photometrischen Messungen werden durch Riboflavin und Metabolite des Salizylazosulfapyridin gestört. 3 Tage vor den Untersuchungen muß die Substitution mit Pankreasenzympräparaten beendet werden. Die diagnostische Wertigkeit wird in ähnlicher Weise wie bei der Chymotrypsinausscheidung mit dem Stuhl eingeschätzt (s. oben); allerdings scheint die Sensitivität bei Fällen mit leichter und mittelschwerer Pankreasinsuffizienz größer zu sein.

\section{NBT-PABA-Test}

Der NBT-PABA-Test wird ähnlich wie der Fluoreszeindilaurattest durchgeführt. Aus dem Medikament (NBT-PABA) erfolgt in der Gegenwart von Chy- 
motrypsin die Abspaltung von resorptionsfähiger Paraaminobenzoesäure, die anschließend im Urin gemessen werden kann. Über die Versuchsbedingungen (Menge des Pharmakons, Probemahl, Urinsammelzeiten, Kontrollversuch) liegen unterschiedliche Empfehlungen vor. Im Handel ist eine Testpackung (PFTRoche) und ein Reagenziensatz (PABA-Test Roche) erhältlich. Das Ergebnis wird durch die gleichzeitige Gabe von Pankreassubstitutionspräparaten, Antazida, Sulfonamide und Sulfonylharnstoffen gestört; weitere Störquellen sind die Leber- und Niereninsuffizienz. Für die diagnostische Wertigkeit gelten die gleichen Angaben wie für den Fluoreszeindilaurattest (s. oben). Beide Teste können auch im gleichen Untersuchungsgang durchgeführt werden, was möglicherweise die diagnostische Sicherheit verbessert.

\section{Weitere Testverfahren}

Von der Vielzahl der in der Literatur beschriebenen Tests des exokrinen Pankreas sollen hier folgende Verfahren erwähnt werden:

Stuhlfettausscheidung: Als Folge der Malassimilation erscheint vermehrt Fett im Stuhl; gleichzeitig ist auch das Stuhlgewicht erhöht (s. 4.4). Beide Tests werden besonders zur Kontrolle der Substitutionstherapie verwendet. Als Suchverfahren erscheinen sie zu unspezifisch.

Laktoferrin ist ein Glykoprotein, das bei chronischer Pankreatitis vermehrt sezerniert wird. Die Bestimmung läßt sich in einfacher Weise mittels radialer Immundiffusion unter Verwendung von LC-Partigenplatten (Behringwerke) durchführen. Das Material wird beim Sekretin-Pankreozymin-Test entnommen.

Glukosetoleranztests. Schwere Pankreasleiden gehen mit einer Beeinträchtigung des endokrinen Pankreas einher. Als Folge kommt es zur gestörten Glukosetoleranz oder zum manifesten Diabetes mellitus. Zur Diagnostik können die Bestimmung des postprandialen Blutzuckerspiegels (d. h. 1-2 h nach einer Mahlzeit), das Blutzuckertagesprofil oder - als empfindlichste Prüfung - der orale Glukosetoleranztest dienen.

\subsection{Akute Pankreatitis}

Nach der revidierten Klassifikation von Marseille ist die akute Pankreatitis klinisch durch Bauchschmerzen und durch erhöhte Pankreasenzyme im Blut und/ oder Urin definiert. In den meisten Fällen nimmt sie einen gutartigen Verlauf; schwere Attacken können jedoch zu Schock, Nieren- und Leberinsuffizienz sowie letalem Ausgang führen. Die Erkrankung kann als einmalige Episode oder als Rezidiv auftreten [3]. - In dieser Beschreibung wird die Vielgestaltigkeit und Bedrohlichkeit des Krankheitsbildes deutlich, die für den Arzt erhebliche Probleme bei Diagnostik und Therapie bedeuten können.

Ätiologie, Pathogenese. Trotz vieler Bemühungen sind die Ursachen und Mechanismen, die zu einer akuten Pankreatitis führen, nur zum Teil geklärt wor- 
den. Eine Rolle mag hier spielen, daß die Bauchspeicheldrüse wegen der verborgenen Lage nur schwer untersucht werden kann und durch den Gehalt an digestiven Enzymen meistens zerstört erscheint. Als die wichtigsten Ursachen akuter Pankreatitis gelten die Choledocholithiasis und der Alkoholismus. Eine Zusammenstellung bekannter Gründe bringt die Übersicht.

Ursachen der akuten Pankreatitis

Mechanische Faktoren

- Choledocholithiasis

- Verletzungen, Bauchoperationen (Gallenwege, Magen)

- Obstruktion des Pankreasgangs (Geschwülste; Askaris; Anomalien, z. B. Pancreas divisum)

- Diagnostische Untersuchungen (Feinnadelpunktionen; endoskopisch-retrograde Pankreatographie)

Stoffwechselveränderungen

- Alkoholismus

- Hyperlipoproteinämie (Typ I, Typ V)

- Hyperkalzämie, Hyperparathyreoidismus

- Medikamente (Diuretika; Östrogene; Azathioprin; Methyldopa; Sulfonamide; Tetrazykline; Glukokortikoide)

- Genetische Faktoren (familiäre Pankreatitis)

Infektionen

- Mumps

- Coxsackie-Virus

- Virushepatitis

Gefäßfaktoren

- Periarteriitis nodosa

- Embolie

Erkrankungen des Zwölffingerdarms

- Peptisches Ulkus

- Divertikel

- Stenosen

Unter den mechanischen Faktoren stehen Gallensteine an der ersten Stelle. $\mathrm{Da}$ Pankreasgang und Gallengang gemeinsam an der Papilla Vateri in den Darm einmünden, ergibt sich eine Beziehung zwischen beiden Gangsystemen. Bei der „biliären Pankreatitis“ soll durch Gallengangsteine an der Papille ein Rückstau des Bauchspeichels oder ein Übertritt der Galle in den Pankreasgang bewirkt und damit die Entstehung einer Entzündung begünstigt werden. Unterstützt wird diese Hypothese durch die häufige Nachweisbarkeit kleiner Gallensteine im Stuhl dieser Patienten (ca. 90\% der Fälle), wobei jene offensichtlich durch die Papille in den Darm übergetreten sind. Dies erklärt auch, warum bei einem Teil der Betroffenen in der Gallenblase bzw. im Gallengang keine Steine mehr anzutreffen sind. Ein Rückstau des Bauchspeichels mit erhöhtem Druck im Gangsystem soll ebenfalls bei den Entzündungen infolge Pankreasgangobstruktion eine Rolle spielen. Diskutiert werden hier 2 Mechanismen: 1. Durch den erhöhten Druck werden kleinere Gänge zerrissen; Bauchspeichel kann in das Parenchym übertreten, wo autodigestive Vorgänge einsetzen. 2. Der erhöhte Druck verhindert die Sekretion der Enzyme; autodigestive Vorgänge beginnen in den Drüsenzellen. 
Alkoholismus gilt als die häufigste Ursache der akuten Pankreatitis. Unklar ist jedoch, inwieweit es sich bei diesen Fällen um vorgeschädigte Drüsen handelt. Es sprechen jedenfalls viele Beobachtungen dafür, daß in der Regel die akute Exazerbation einer chronischen, evtl. symptomarm verlaufenden Entzündung vorliegt. Eine Diskussion der möglichen Pathomechanismen findet sich im folgenden Kapitel über die chronische Pankreatitis.

Von verschiedenen Medikamenten sind als ungünstige Nebenwirkung Bauchspeicheldrüsenentzündungen bekannt geworden (s. S. 472). Es handelt sich hierbei in der Regel um seltene, einzeln beobachtete Fälle, bei denen auch andere Faktoren möglicherweise eine Rolle spielten. Dies gilt für Glukokortikoide. Eine endgültige Wertung der Kausalzusammenhänge ist deshalb nicht möglich.

Verschiedene Virusinfekte können das Pankreas mitbetreffen. In den meisten Fällen handelt es sich um milde Begleitreaktionen, die klinisch nicht im Vordergrund stehen. Etwa 7\% der Patienten mit Hyperparathyreoidismus sollen an einer akuten Pankreatitis leiden. Eine wichtige Rolle könnte hier die Hyperkalzämie spielen, durch die die Sekretion stimuliert würde. Neuere Untersuchungen haben jedoch Kausalitätsbeziehungen nicht bestätigen können.

Patienten mit stark erhöhten Serumtriglyzeridspiegeln (Hyperlipoproteinämie Typ I und Typ $V$ nach Fredrickson) klagen - u. U. abhängig von den jeweiligen Fettkonzentrationen - über Bauchschmerzen, als deren Ursache Bauchspeicheldrüsenentzündungen gefunden werden. Eine Rolle sollen schädliche Wirkungen von freien Fettsäuren spielen, die aus den Serumtriglyzeriden im Pankreas durch Lipase freigesetzt werden.

Zirkulationsstörungen, Verletzungen durch Unfälle, Operationen, Unterkühlung etc. können zur akuten Pankreatitis führen. Die beteiligten Mechanismen sind weitgehend rätselhaft. Bei etwa $10 \%$ der Patienten läßt sich keine Krankheitsursache finden (idiopathische Pankreatitis).

Im Zentrum der Überlegungen zur Pathophysiologie der akuten Pankreatitis steht die Selbstverdauung durch die exkretorischen Enzyme. Unter physiologischen Bedingungen gibt es verschiedene Schutzmechanismen: 1. Die Abgabe der Enzyme als inaktive Moleküle, 2. Proteaseninhibitoren, die von den Azinuszellen gebildet und in den Speichel sezerniert werden; sie hemmen etwa die Wirkung von Trypsin. 3. Die Abtrennung der Enzyme in den Azinuszellen vom Zytoplasma; die an der Herstellung beteiligten Strukturen - Ribosomen, Golgi-Apparat, Zymogengranula - binden die Enzyme fest ein, so daß schädliche Wirkungen an den Zellstrukturen verhindert werden. - Bei der Entstehung der akuten Pankreatitis sind möglicherweise Störungen an diesen Schutzmechanismen beteiligt. Unklar ist allerdings, inwieweit die Selbstverdauung der Anfang ist oder ob autodigestive Vorgänge sich als Reaktion auf einen anderen, unbekannten Prozeß entwickeln. Die Rolle der aktivierten Enzyme wird durch verschiedene Beobachtungen sowohl bei Patienten als auch bei Tierexperimenten belegt.

Am Anfang der Pankreatitis steht wahrscheinlich die Zellschädigung. Die weiteren Kennzeichen sind die entzündliche Infiltration, Ödembildung und Zellnekrosen. Hinzu kommen Fettnekrosen und u. U. Pseudozysten, Aszites oder - bakteriell infizierte - Abszesse. Nach der revidierten Marseiller Klassi- 
fikation sind bei der milden Form peripankreatische Fettnekrosen und ein interstitielles Ödem vorhanden; Pankreasnekrosen sind in der Regel nicht nachweisbar. Bei der schweren Verlaufsform entwickeln sich ausgedehnte peri- und intrapankreatische Fettnekrosen, Parenchymnekrosen und Blutungen. Die Läsionen können sowohl lokalisiert als auch diffus erscheinen. Die Fettnekrosen werden auf die Freisetzung von Lipasen zurückgeführt. Bisweilen werden nicht nur das Pankreas und seine Umgebung, sondern auch das Unterhautfettgewebe befallen, was zu sichtbaren Veränderungen führen kann. Weitere Kennzeichen schwerer Verlaufsformen sind Hypovolämie, Hypotension, Hypalbuminämie, Hypokalzämie, Nierenversagen und Lungenversagen (ARDS). Sie werden durch verschiedene, z. T. hypothetische Mechanismen erklärt. So sollen die Kreislaufreaktionen durch Flüssigkeitsverluste in das Interstitium und durch vasoaktive Substanzen aus dem Pankreas verursacht werden; Lungen- und Nierenschäden sind möglicherweise die Folge von Membranschäden durch zirkulierende Phospholipase; die Serumkalziumverluste gehen evtl. auf die Ausfällung mit Fettnekrosen, auf eine Resistenz der Knochengewebe gegenüber Parathormon oder auf eine vermehrte Ausschüttung von Thyreokalzitonin zurück. Von besonderem Interesse wäre auch die Beantwortung der Frage nach den Faktoren, die für den Übergang der milden in die gefährliche schwere Verlaufsform verantwortlich sind. Diskutiert werden hier Veränderungen der Mikrozirkulation des Pankreas, die zu ungünstigen ischämischen Reaktionen führen sollen. Aufgrund klinischer Parameter läßt sich bereits frühzeitig eine schwere Verlaufsform prognostizieren (s. unten); dieser Befund spricht dafür, da $ß$ in einem relativ frühen Krankheitsstadium der Ablauf der Bauchspeicheldrüsenentzündung festgelegt ist.

Mit dem Abklingen der entzündlichen Erscheinungen normalisieren sich die klinischen, morphologischen und u. U. funktionellen Auffälligkeiten. Bei einigen Fällen verbleiben als Rest Narben oder Pseudozysten. Nur selten wird der Übergang in eine chronische Pankreatitis beobachtet [3].

Klinik. Das führende Zeichen bei etwa 95\% der Patienten mit akuter Pankreatitis ist der Leibschmerz. Er beginnt in der Regel plötzlich und steigert sich innerhalb von Stunden zu maximaler Intensität. Häufiger soll ein üppiges Mahl vorausgehen. Der Schmerz wird meistens in der Gegend des Pankreas empfunden; Erkrankungen im Pankreaskopf können allein zu Schmerzen im rechten Oberbauch führen, was zu Fehldiagnosen Anlaß gibt. Eine Erklärung für dieses Phänomen ist die entwicklungsgeschichtliche Herkunft von Anteilen der rechten Bauchspeicheldrüse aus dem ventralen Pankreas. Schmerzen in der Nabelgegend und im Unterbauch sind vergleichsweise selten. Schmerzausstrahlungen erfolgen evtl. in die linke Schulter. Der Schmerzcharakter ist zumeist hell und schneidend „wie ein Messer, das in den Leib gestochen wird“. Ein weiteres Zeichen ist das Erbrechen, das bei einzelnen Patienten im Vordergrund stehen kann. Ein Teil der Betroffenen klagt auch über Meteorismus, Fieber oder Subileus (Tabelle 8.2).

Bei der körperlichen Untersuchung ist die Spannung der Bauchdecken bei etwa 50\% der Fälle im Sinne eines „Gummibauches“ erhöht. Weitere Befunde sind Aszites, Pleuraerguß (meist linksseitig), Schockzeichen sowie Oligurie und 
Tabelle 8.2. Beschwerden und Befunde bei akuter Pankreatitis (nach verschiedenen Statistiken)

\begin{tabular}{ll}
\hline & $\begin{array}{l}\text { Häufigkeit } \\
{[\%]}\end{array}$ \\
\hline Schmerzen & 95 \\
Schmerzausstrahlung in den Rücken & 50 \\
Übelkeit, Erbrechen & $75-90$ \\
Meteorismus & $70-80$ \\
Subileus & $50-80$ \\
Fieber & $12-80$ \\
Gummibauch & 50 \\
Tastbarer Pankreastumor & $6-20$ \\
Aszites & 40 \\
Pleuraerguß & $20-30$ \\
Blutdruckabfall, Tachykardie & $30-50$ \\
Oligurie, Anurie & 10 \\
Hautzeichen & 10 \\
Chvostek positiv & $10-20$ \\
\hline
\end{tabular}

Anurie. Das Pankreas ist in 6-20\% der Betroffenen als Tumor zu tasten. Schwere Erkrankungen gehen mit einer Hyperglykämie oder einer Hypokalzämie einher, was gegebenenfalls an vermehrtem Durst bzw. an tetanischen Zeichen (Chvostek etc.) erkannt werden kann. Hautveränderungen können für die Einschätzung der Pankreatitis bedeutungsvoll sein: Beobachtet werden Rötungen des Gesichtes, subkutane Fettnekrosen, die als schmerzhafte rote Knoten meist an den unteren Extremitäten, Gesäß oder Stamm erscheinen sowie Ekchymosen aufgrund von retroperitonealen Blutungen an den Flanken (GreyTurner-Zeichen) oder um den Nabel (Cullen-Zeichen).

Der Verlauf ist bei etwa 90\% der Patienten komplikationslos. Die Schmerzen klingen nach 2-5 Tagen ab; das gleiche gilt für die anderen Symptome. Bei den Laborparametern zeigen sich die Veränderungen in der Regel für längere Zeit (s. unten). Diese milde Verlaufsform wird auch als „ödematöse Pankreatitis" bezeichnet (Abb. 8.5). Bedrohlicher sind dagegen die schweren Erkrankungen, die auch entsprechend den morphologischen Veränderungen als „,hämorrhagisch-nekrotisierende Pankreatitis" klassifiziert werden. Aufgrund der Komplikationen - Schock, Nierenversagen, Lungenversagen, Ileus, Enzephalopathie, Verbrauchskoagulopathie, intestinale Blutung, Sepsis etc. - liegt die Letalität selbst bei optimalen therapeutischen Voraussetzungen in der Größenordnung $50-80 \%$. Die Ausbildung von Pseudozysten und von Abszessen gilt als Spätkomplikation, die bei allen Formen beobachtet werden kann.

Diagnostik. Bei den diagnostischen Bemühungen ergibt sich eine doppelte Zielsetzung: 1. Bestätigung der Diagnose. 2. Klassifikation im Hinblick auf die Ausbildung einer hämorrhagisch-nekrotisierenden Pankreatitis und der Komplikationen.

Für die Bestätigung der Verdachtsdiagnose dienen zuerst die klinisch-chemischen Tests. Hierzu zählen die Spiegel von Amylase und Lipase im Serum bzw. 

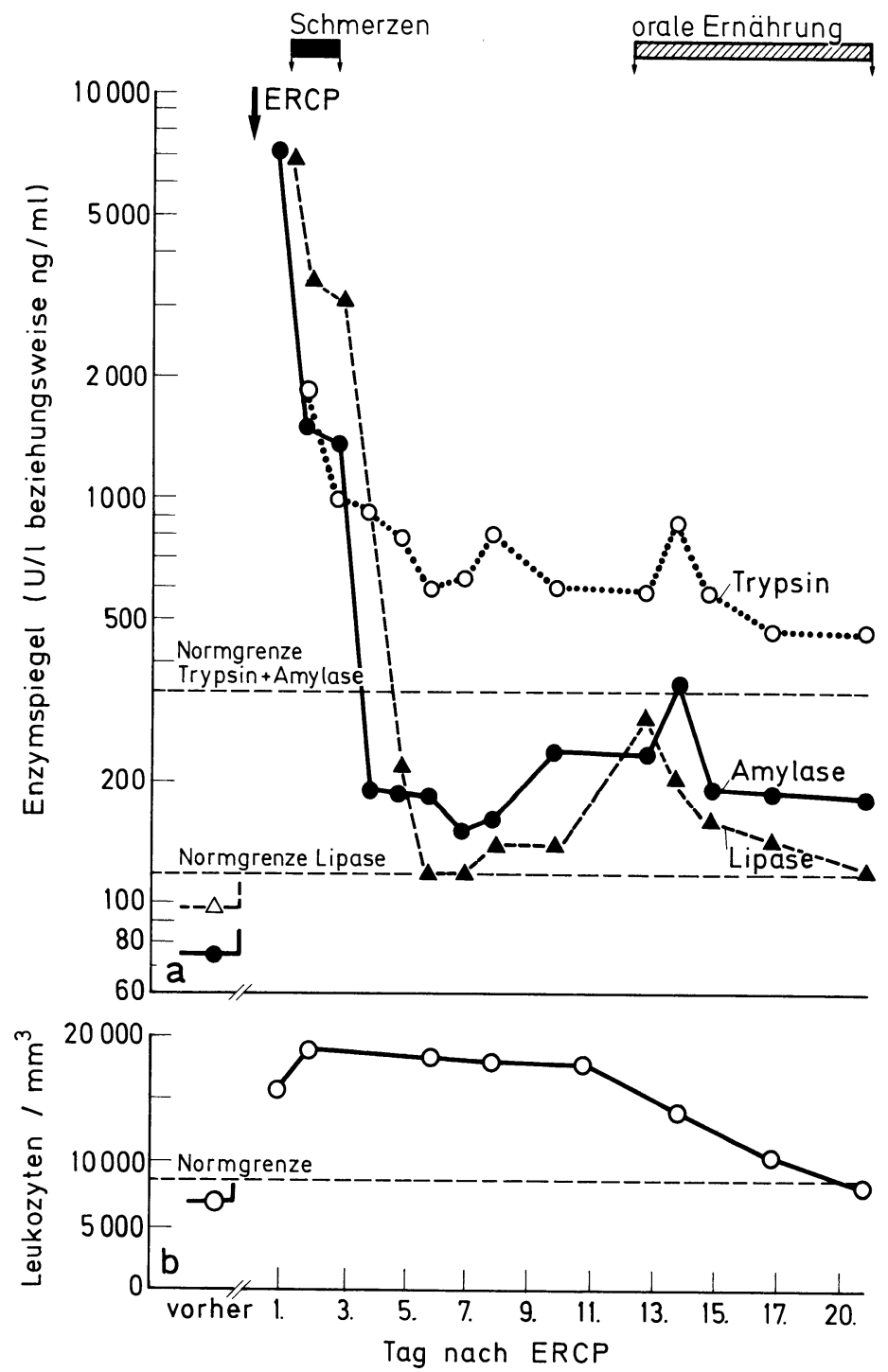

Abb. 8.5a, b. Ödematöse Pankreatitis. Serumspiegel von Amylase, Lipase und Trypsin (a) sowie Serumleukozytenzahl (b) während einer Beobachtungszeit von 21 Tagen. Die Ursache war hier eine endoskopisch retrograde Pankreatographie. - Schmerzen und stärkere Enzymentgleisungen waren nur etwa 3 Tage vorhanden. Trotz weitgehender Beschwerdefreiheit waren leicht erhöhte Lipase- und Trypsinaktivitäten sowie eine Leukozytose für mehrere Wochen vorhanden

von Amylase im Urin. Wertvoll ist auch der Nachweis einer Leukozytose im Blutbild. In den meisten Fällen ist in der Initialphase bei diesen Parametern ein von der Norm abweichender erhöhter Meßwert zu erheben; allerdings können selbst bei schweren Verläufen Normalbefunde existieren. Im Vergleich ist Lipase häufiger pathologisch erhöht als Amylase, wobei durch die gleichzeitige Bestimmung beider Enzyme die diagnostische Sicherheit erhöht werden kann [4]. 
Der diagnostische Wert von Amylase und Lipase ist auch unter 8.4.1 dargestellt. Die Leukozytenzahl ist in der Größe zwischen 10 und $25000 / \mathrm{mm}^{3}$; in seltenen Fällen gibt es auch leukämoide Reaktionen mit Werten bis $60000 / \mathrm{mm}^{3}$. Weitere pathologische Laborbefunde sind vor allem bei schweren Erkrankungen im Blut erhöhte Werte bei Blutzucker, Hämoglobin, Hämatokrit, harnpflichtigen Substanzen, Triglyzeriden, Transaminasen, Laktatdehydrogenase; desgleichen erniedrigte Werte bei Kalzium, Magnesium, arterieller Sauerstoffspannung, Gerinnungsenzymen, Thrombozyten; metabolische Alkalose. Der Serumspiegel von C-reaktivem Protein scheint ein Maß für die Pankreasnekrose zu sein. Methämalbumin erscheint im Serum als Abbauprodukt des Hämoglobins im Verlauf der hämorrhagisch-nekrotisierenden Pankreatitis; eine größere diagnostische Bedeutung konnte dieser Parameter wegen der ungenügenden diagnostischen Empfindlichkeit und Spezifität nicht erlangen.

Mit den verschiedenen bildgebenden Verfahren lassen sich morphologische Veränderungen erfassen. Bewertet werden die Größe, die Lumenstruktur einschließlich Zystenbildung sowie Verkalkungen beim Pankreas. Daneben lassen sich Aszites, Pleuraerguß, Abszedierungen, Gallensteine, Abflußbehinderungen der Galle etc. darstellen. Andererseits schließen normale Befunde eine akute Pankreatitis nicht aus. In den röntgenologischen Leeraufnahmen des Abdomens zeigen sich vor allem Komplikationen: Ileus, Perforation, Aszites, Verdrängungen lufthaltiger Darmschlingen; Pankreasverkalkungen gelten als Zeichen der chronischen Entzündung. Beim Thoraxröntgenbild findet man ggf. Ergüsse (meist linksseitig) und pulmonale Infiltrate. Die Sonographie ermöglicht sowohl Aussagen über das Pankreas (Abb. 8.6) als auch über die Gallenwege einschließlich Steinen, Aszites, Pleuraergußbildung usw. Leider wird die diagnostische Bedeutung durch den häufigen Meteorismus eingeschränkt; bei mehr als der Hälfte der Patienten ist das Pankreas deshalb nicht darstellbar. Wegen der Möglichkeit, Gallensteine, Galleabflußbehinderungen und Flüssigkeitsansammlungen ohne großen Aufwand zu diagnostizieren, wird man - sofern dies möglich ist - trotzdem ein Sonogramm anfertigen. Wertvoll sind auch Wiederholungsuntersuchungen, weil hier die Entwicklung der Erkrankung verfolgt werden kann; oftmals gelingt es dann, eine Darstellung der Bauchspeicheldrüse zu erhalten. Als die überlegene Methode gilt die Computertomographie, weil sie in fast allen Fällen eine ausreichende Beurteilung des Pankreas ermöglicht (Abb. 8.7). Hervorragend gelingt auch die Darstellung von peripankreatischen Flüssigkeitsansammlungen, die sich am häufigsten in der Bursa omentalis, zwischen Pankreas und Nieren, sowie im Mesocolon transversum finden lassen. Vor allem in unklaren Fällen wird man diese aufwendige Methode einsetzen.

In den letzten Jahren ist die Duodenoskopie als weiteres diagnostisches Verfahren in den Vordergrund getreten. Bei Patienten mit biliärer Pankreatitis ist es möglich, einen im Bereich der Papille eingeklemmten Stein zu sehen und gegebenenfalls zu entfernen. Das Gangbild der Bauchspeicheldrüse ist in der endoskopisch retrograden Darstellung unauffällig.

\section{Klassifikation der akuten Pankreatitis}

Es wurde bereits dargelegt, daß die überwiegende Zahl der akuten Bauchspeicheldrüsenentzündungen leicht und ohne Komplikationen verläuft (,ödematö- 


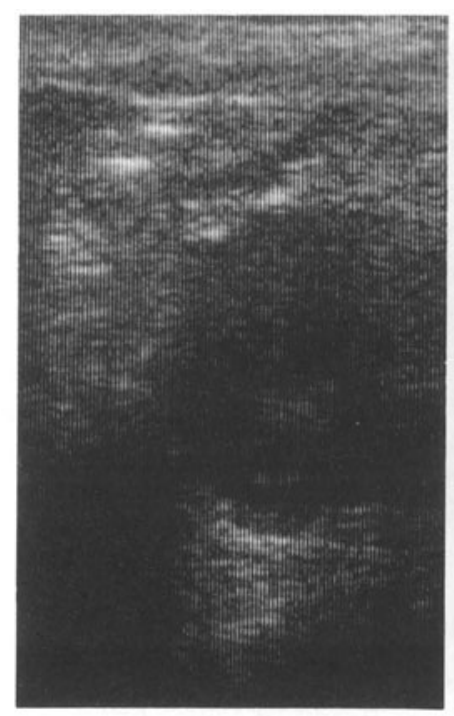

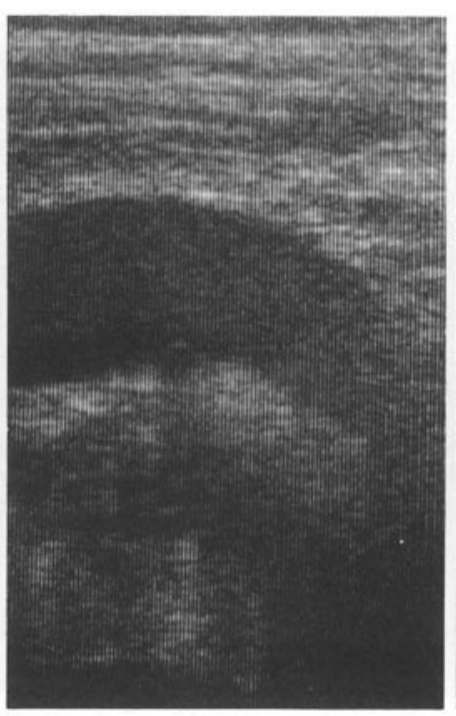

b

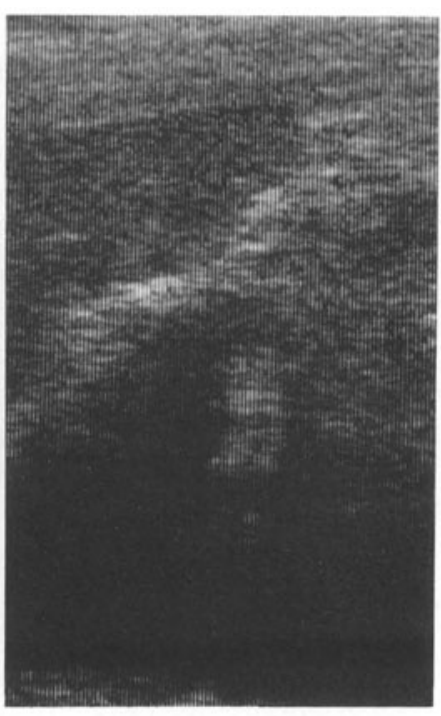

c

Abb. 8.6a - c. Sonographische Befunde bei akuter Pankreatitis. Im Vordergrund steht ein entzündliches Ödem, welches zu einer Vergrößerung der Drüse führen kann; durch den vermehrten Gehalt an Flüssigkeit erscheint ggf. das Organ echoarm (= schwarz). Ein normales sonographisches Erscheinungsbild der Bauchspeicheldrüse schließt eine akute Entzündung nicht aus.

a Mächtige Auftreibung des Pankreaskopfes mit inhomogenem Binnenmuster. Links oben im Bild ist der Leberrand angeschnitten. - Die Schnittführung ist ähnlich wie in Abb. 1.8.

b Längsschnitt durch Pankreaskörper (links) und -schwanz (rechts). Im Durchmesser ist das Pankreas auf über $3 \mathrm{~cm}$ verdickt. Die Binnenstruktur ist weitgehend homogen und echoarm; die Grenze zur Umgebung ist scharf. - Wegen der Schnittführung vgl. Abb. 1.12. Die Untersuchung erfolgte hier nicht durch die Leber sondern durch den Magen; er ist andeutungsweise an der Wandreflexion erkennbar.

c Pankreasnekrose mit peripankreatischem Exsudat, welches bis zur Milz (links oben im Bild, vgl. Abb. 1.14) reicht.

se Pankreatitis“). In den letzten Jahren sind vielfältige Bemühungen angestellt worden, solche Kenngrößen zu definieren, die frühzeitig den Übergang in die gefährliche, komplizierte Form anzeigen (,hämorrhagisch-nekrotisierende Pankreatitis"). Die verschiedenen klinischen Zeichen - Schock, Nierenversagen, Ileus, Pleuraerguß etc. - erwiesen sich als wenig brauchbar, da sie erst im fortgeschrittenen Stadium auftreten. Auch sind Versuche mißlungen, ein objektives Merkmal zu finden, das allein für eine prognostische Aussage ausreichen würde. Von Ranson et al. wurde deshalb vorgeschlagen, die Kombination von 11 Kriterien zu bewerten. Nach deren Erfahrungen bedeutet das Vorliegen von 7-8 Merkmalen eine Letalität von 100\%; wurden 0-2 Merkmale gefunden, so war die Prognose günstig; bei 3-6 nachweisbaren Merkmalen war der Krankheitsverlauf schwer, ein Teil der Betroffenen mußte länger als 1 Woche intensiv behandelt werden oder starb [10]. Von verschiedenen Autoren sind in den letzten Jahren Modifikationen dieses Merkmalskataloges mitgeteilt worden. So 


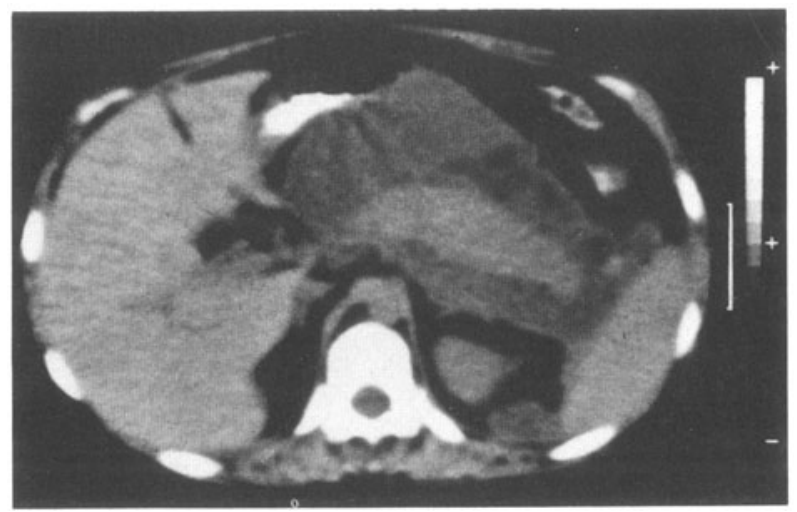

Abb. 8.7. Computertomogramm bei akuter Pankreatitis mit peripankreatischer Exsudation, welche bis zur Fascia Gerota und zur Mesenterialwurzel reicht. Das Pankreas selbst erscheint nur gering betroffen. Im Vordergrund steht die Peripankreatitis (häufiger Befund). - Pankreasnekrosen, -abszedierungen oder -pseudozysten würden sich durch eine Inhomogenität der Binnenstruktur und eine Vergrößerung des Drüsenkörpers zeigen. Eine weitere Differenzierung des Befundes ist anhand der durchbluteten Areale möglich, welche sich nach Gabe von Kontrastmittel darstellen lassen.

wurde als weiteres Kriterium die Peritoneallavage angegeben, wo mehr als $10 \mathrm{ml}$ eines dunkel gefärbten amylasereichen Aszites eine ungünstige Prognose zeigen sollen. Ein anderer Einwand bezog sich auf die zumeist älteren Patienten mit der durchwegs günstiger verlaufenden biliären Pankreatitis; hier wurde befürwortet, das Kriterium „Alter über 55 Jahre“ wegzulassen und die Grenze der Transaminaseaktivität auf $200 \mathrm{U} / 1$ zu senken. - Prognostische Informationen lassen sich auch vom Erscheinungsbild des Pankreas bei der Probelaparotomie erhalten, wo Hämorrhagien oder Phlegmonen einen ungünstigen Verlauf signalisieren. Allerdings wird nur bei einer Minderzahl der Patienten dieser Eingriff vorgenommen; zum anderen ist die Beurteilung des Pankreas wegen der retroperitonealen Lage und der häufig überwiegenden Peripankreatitis (s. Abb. 8.7) erschwert.

\section{Prognostische Frühzeichen für eine schwergradige Pankreatitis (Nach [10])}

Bei der Aufnahmeuntersuchung

- Alter > 55 Jahre

- Leukozytenzahl > $16000 / \mathrm{mm}^{3}$ Blut

- Serumglukosespiegel $>200 \mathrm{mg} / \mathrm{dl}$

- Serumlaktatdehydrogenase $>350$ IE/1

- Serumglutamatoxalazetattransaminase $>250$ Fraenkel-E/dl

Während der initialen 48 Stunden

Abfall des Hämatokrits $>10 \%$

Serumharnstoff-N Anstieg $>5 \mathrm{mg} / \mathrm{dl}$

Serumkalziumspiegel unter $8 \mathrm{mg} / \mathrm{dl}$

Arterielle Sauerstoffspannung unter $60 \mathrm{~mm} \mathrm{Hg}$

Basendefizit > $4 \mathrm{mVal} / \mathrm{l}$

Geschätzte Flüssigkeitsretention $>61$ 
Differentialdiagnose. Bei leichten Erkrankungen sind vor allem auch folgende Diagnosen zu erwägen: akute Cholezystitis; peptisches Ulkus (evtl. Penetration in das Pankreas von der dorsalen Wand des Bulbus duodeni); Porphyrie; Neuralgie; basale Pleuritis; Reizkolon. Erhöhte Pankreasenzymspiegel im Serum werden bei verschiedenen extrapankreatischen Leiden gefunden, was zu falschen Diagnosen führen kann (s. 8.4.1). In schweren Fällen kommen differentialdiagnostisch Verschlüsse der intestinalen Gefäße, Strangulationsileus, rupturierte Aortenaneurysmen, Myokardinfarkt sowie komplizierte Verläufe bei peptischem Ulkus und Cholezystitis in Betracht. Die größte diagnostische Schwierigkeit entsteht bei den Fällen, wo Leibschmerzen als führendes Symptom fehlen. Hier ist ein unklarer Schock oder ein unklares Nierenversagen evtl. das einzige Zeichen.

Therapie. Eine kausal wirksame Behandlung der akuten Pankreatitis ist nicht bekannt. Man gewinnt den Eindruck, als würde die Erkrankung unabhängig von äußeren Bedingungen ihren Lauf nehmen. Hierfür spricht, daß man bereits am Beginn aufgrund von gewissen Merkmalen Angaben über den Krankheitsverlauf machen kann (s. oben).

Versuche, durch Medikamente mit Hemmwirkungen auf die Bildung (Atropin, Glukagon, Kalzitonin, Somatostatin) oder den katalytischen Effekt (Aprotinin, Phospholipase- $\mathrm{A}_{2}$-Inhibitoren) der exkretorischen Pankreasenzyme einen Einfluß auf die Selbstverdauungsvorgänge zu gewinnen, sind bisher gescheitert. Inwieweit bei biliärer Pankreatitis durch die Entfernung der Choledochussteine der Krankheitsverlauf geändert werden kann, ist noch unklar, zumal bei diesen Patienten die Entzündungen oft leichtgradig erscheinen. Die Therapie beruht somit auf symptomatischen Maßnahmen, deren Wert nur teilweise begründet ist [2]. Sie lassen sich in folgender Weise zusammenfassen:

1. Grundsätzlich Behandlung im Krankenhaus, am besten unter intensiver Überwachung. Von Interesse sind insbesondere folgende Parameter: Blutdruck, Puls, Urinausscheidung/Flüssigkeitsbilanz, Amylase, Lipase, Hämoglobin, Hämatokrit, Leukozyten, Kalzium, Harnstoff, Thrombozytenzahl, Gesamteiweiß, Albumin, C-reaktives Protein. Sie sollten gegebenenfalls mehrmals täglich gemessen werden.

2. Beseitigung der möglichen Noxen: Alkohol, Medikamente etc.

3. „Ruhigstellung des Pankreas“ durch parenterale Ernährung, Dauerabsaugung des Mageninhalts mittels Sonde. Histamin- $\mathrm{H}_{2}$-Antagonisten hemmen die Bildung der Magensäure und damit die reaktive Ausschüttung von Bikarbonat beim Übertritt ins Duodenum; der therapeutische Wert wird jedoch hauptsächlich in der Blutungsprophylaxe gesehen.

4. Schockbekämpfung, Ausgleich der Serumelektrolyte. In den ersten $24 \mathrm{~h}$ sollten 3-81 Flüssigkeit mit Elektrolyten und Zuckern (Glukose, Fruktose) zugeführt werden. Bei Schock werden Humanalbumin bzw. Plasmaexpander und gegebenenfalls Dopamin empfohlen. Wichtig ist auch die Bekämpfung der häufig zu beobachtenden Hypokaliämie durch die Kaliumgabe; wegen der möglichen ungünstigen Wirkungen bei der Pankreatitis wird man Kalzium nur vorsichtig substituieren. 
5. Antibiotika sind in ihrem therapeutischen Wert umstritten; trotzdem ist die Gabe von breit wirksamen Präparaten (Ampizillin, Mezlozillin) in schweren Fällen üblich.

6. Als Schmerzmittel werden Procain, spasmolytisch-analgetisch wirksame Mischpräparate (Buscopan comp., Baralgin) oder Opiate mit geringer Wirkung am Sphincter Oddi (Dolantin) bzw. Pentazocin empfohlen.

7. Bei respiratorischer Insuffizienz mit Abfall des $\mathrm{pO}_{2}$ unter $65 \mathrm{~mm} \mathrm{Hg}$ ist die Gabe von Sauerstoff bzw. die maschinelle Beatmung mit positivem endexspiratorischem Druck notwendig.

8. Das Nierenversagen signalisiert eine schlechte Prognose. Inwieweit durch Mannitol (250 ml einer 20\%igen Lösung rasch i.v.) die Entwicklung verhindert werden kann, ist unklar. Hämodialysen sind unwirksam. Der Wert von Peritonealdialysen ist strittig [8].

9. Eine Verbrauchskoagulopathie wird nach den Regeln der Intensivmedizin behandelt: Substitution der Gerinnungsfaktoren durch Gabe von Fresh Frozen Plasma, Antithrombin III, Heparin etc.

10. Bei biliärer Pankreatitis mit Steineinklemmung - ausgewiesen durch Anamnese, Steinbefund im Sonogramm und Zeichen der Cholestase - wird die endoskopisch retrograde Cholangiographie (ERC) empfohlen. Gegebenenfalls kann bei der gleichen Gelegenheit der Stein durch Papillotomie etc. entfernt werden. In diesen Fällen soll sich die Pankreatitis rasch bessern.

11. Chirurgische Eingriffe sind in ihrem Wert umstritten. In der Initialphase wird manchmal die Entscheidung zur diagnostischen Laparotomie gefällt, wenn innerhalb von 2-3 Tagen eine unerklärliche Verschlechterung des Zustandes eintritt bzw. wenn durch die bildgebenden Verfahren (Sonographie, Computertomographie mit intravenöser Kontrastmittelgabe zur Identifizierung der durchbluteten Areale) keine ausreichenden Informationen erhalten werden können. Die Frage, inwieweit durch eine Entfernung der Nekrosen bzw. Nekrosestraßen bei hämorrhagisch-nekrotisierender Pankreatitis die schlechte Prognose günstig beeinflußt werden kann, wird unterschiedlich beantwortet.

In der 2. - 10. Krankheitswoche können sich Abszesse oder große Zerfallshöhlen mit Pankreassequestern bilden: die Betroffenen entwickeln nach einem symptomarmen Intervall Leibschmerzen, Fieber, Leukozytose etc. Mit den bildgebenden Methoden kann der Lokalbefund dargestellt werden. Hier sind operative Maßnahmen (Drainagen, Ausräumung) besser begründbar. Bedrohlichste Komplikationen (Perforation in die Bauchhöhle, retroperitoneale Sepsis, Blutungen etc.) können evtl. vermieden werden.

Eingriffe an den Gallenwegen bei Gallen- und Gallengangsteinen erfolgen am besten im Intervall nach dem Abklingen der akuten Erscheinungen. Nur selten ist bei akuter Steineinklemmung an der Papille eine Laparotomie nötig; in diesem Zusammenhang sei auf die Möglichkeit verwiesen, auf endoskopischem Weg durch Papillotomie und Steinextraktion zu therapieren (s. oben).

12. Pankreaspseudozysten können sich innerhalb von 2-4 Wochen bei allen Verlaufsformen der akuten Pankreatitis entwickeln. Sie besitzen zumeist Verbindungen zum Pankreasgangsystem und bilden sich in der Hälfte der 
Fälle spontan zurück. Für therapeutische Eingriffe wird eine Beobachtungszeit von 6 Wochen empfohlen, während der sich die Rückbildungstendenz abschätzen läßt bzw. die Festigung der Wandung erfolgen kann. Zur Vermeidung der möglichen Komplikationen (Blutung, Ruptur, Sepsis) wird dann eine Drainageoperation vorgenommen, beispielsweise durch Y-Anastomose mit einer Jejunalschlinge. Der Stellenwert der sonographisch bzw. computertomographisch gezielten Aspiration mittels Feinnadel läßt sich nicht endgültig angeben. Einerseits muß bei den häufiger wiederholten Eingriffen mit septischen Komplikationen gerechnet werden; darüber hinaus ist unklar, inwieweit nekrotisches Material, Zelldebris etc. ausreichend mitentfernt werden kann.

Inwieweit die verschiedenen oben angegebenen Maßnahmen eingesetzt werden, muß jeder Arzt aufgrund seiner Erfahrungen entscheiden. Wichtig erscheinen in den unkomplizierten Fällen vor allem die Nahrungskarenz, die ausreichende parenterale Flüssigkeits- und Elektrolytzufuhr und die Schmerzbekämpfung. Die Wiederaufnahme der oralen Ernährung wird man nach dem Verschwinden der Beschwerden und nach der weitgehenden Normalisierung der klinisch-chemischen Parameter erlauben.

\subsection{Chronische Pankreatitis}

Nach der revidierten Klassifikation von Marseille wird die chronische Pankreatitis als eigenständiges Krankheitsbild von der akuten Bauchspeicheldrüsenentzündung abgegrenzt [3]. Im Gegensatz zur akuten Entzündung wird hier mit dem Abklingen von Krankheitserscheinungen in der Regel keine Rückbildung der Organveränderungen beobachtet. Übergänge zwischen beiden Erkrankungen gelten als selten. Die wichtigsten Symptome sind rezidivierende oder persistierende Leibschmerzen sowie die Pankreasinsuffizienz mit Fettstühlen bzw. Diabetes mellitus.

Ätiologie, Pathogenese. Nach den vornehmlich im Arbeitskreis von Sarles entwickelten Vorstellungen entsteht die chronische Pankreatitis durch eine Behinderung des Speichelflusses [11]. Bei der chronisch obstruierenden Pankreatitis ist die Ursache in einer Verengung des Pankreasganges durch eine Geschwulst, eine Zyste, eine Anomalie (Pancreas divisum) oder eine Entzündung des Sphincter Oddi zu suchen. Die Veränderungen werden im prästenotischen Bereich mit einer Erweiterung der Gänge und Umbau des Parenchyms gefunden; Steinbildungen gehören nicht zum Krankheitsbild. Bei der chronisch kalzifizierenden Pankreatitis manifestiert sich dagegen die Störung in den kleineren Drüsengängen, weil ein ungünstig zusammengesetztes Pankreassekret hier ausfällt und den Fluß behindert. Am Anfang sollen kleinste Präzipitate aus Eiweißen, Kalziumkarbonat etc. stehen. Sie werden entweder weitertransportiert oder bewirken lokale Reaktionen mit Entzündung und Narbenbildung. Später formen sich größere Konkremente, die dann infolge ihres Kalziumgehaltes im Röntgenbild sichtbar werden. Für das Fortschreiten der Erkrankung scheinen narbige Strukturen der Pankreasgänge eine wichtige Rolle zu spielen. 
Die häufigste Ursache der chronisch kalzifizierenden Pankreatitis ist in Mitteleuropa der Alkoholismus. Ähnlich wie bei der alkoholischen Leberschädigung steigt das Erkrankungsrisiko mit der täglich zugeführten Äthanoldosis und der Dauer der Sucht. Frauen reagieren empfindlicher als Männer. Die Mechanismen, welche zur Bildung eines abnormen Pankreassekrets führen, sind weitgehend unbekannt. In diesem Zusammenhang ist die Entdeckung eines „Steinproteins" durch die Arbeitsgruppe von Sarles von Interesse, das die Ausfällung von Kalziumkarbonat verhindern kann, und das bei - seltenen - hereditären Formen von kalzifizierender Pankreatitis nachweislich fehlen kann. Durch Äthanol soll bei entsprechender Prädisposition die Konzentration des Steinproteins im. Speichel vermindert und die Ausfällung von Kalziumkarbonat begünstigt werden. Unabhängig von diesen Vorgängen wird in Analogie zur Leber durch Alkohol eine Verfettung der Azinuszellen mit Mitochondrienveränderungen sowie eine Fibrose erzeugt.

Andere Ursachen von chronisch kalzifizierender Pankreatitis sind die Hyperkalzämie bzw. der primäre Hyperparathyreoidismus und - gehäuft in den Entwicklungsländern - die Eiweißmangelernährung (Kwashiorkor). Man nimmt an, daß hier ebenfalls ein relativer Mangel an Steinprotein eine Rolle spielt.

Hereditäre Formen der chronisch kalzifizierenden Pankreatitis wurden sowohl bei Kindern als auch bei Erwachsenen aufgrund des familiär gehäuften Vorkommens diagnostiziert. Möglicherweise wird die unterschiedliche Manifestation durch verschiedene Grade von Mangel an Steinprotein festgelegt.

Morphologie. Während die Mechanismen, die zur chronischen Pankreatitis führen, bisher nur zum Teil geklärt wurden, sind die morphologischen Veränderungen gut bekannt [3]. Im histologischen Bild sieht man eine unregelmäßige Sklerose mit Zerstörung und Untergang von exokrinem Drüsengewebe. Begleitend sind evtl. verschiedene Grade der Gangerweiterung, die auch unabhängig von Parenchymveränderungen vorkommen. Weitere Merkmale sind entzündliche Infiltrate mit Ödembildung und lokalen Nekrosen. Im Vergleich werden Langerhans-Inseln geringer betroffen. Weitere mögliche Befunde sind Zysten, Pseudozysten, mit und ohne Verbindung zum Gangsystem bzw. mit und ohne Infektion. Aufgrund dieser Sachverhalte wird in der revidierten Klassifikation von Marseille folgende - morphologisch begründete - Einteilung der chronischen Pankreatitis vorgeschlagen:

- Chronische Pankreatitis mit lokaler Nekrose,

- chronische Pankreatitis mit segmentaler oder diffuser Fibrose,

- chronische Pankreatitis mit und ohne Steinbildung,

- chronisch obstruktive Pankreatitis.

Im Gegensatz zu den übrigen Formen der chronischen Pankreatitis, wo mit einem zunehmenden oder dauernden Verlust der Funktionen gerechnet werden muß, ist bei der chronisch obstruktiven Pankreatitis eine Besserung der Leistungsfähigkeit nach Beseitigung der Stenose möglich.

Klinik. Leibschmerzen sind die wichtigsten Beschwerden bei der chronischen Pankreatitis. Sie werden wie bei der akuten Bauchspeicheldrüsenentzündung vorwiegend im linken Oberbauch empfunden: Schmerzen im rechten Ober- 
bauch weisen auf eine Beteiligung des Pankreaskopfes hin. Ausstrahlungen erfolgen häufig gürtelförmig bis zur Wirbelsäule, evtl. auch in die linke Schulter oder zwischen die Schulterblätter. In der Regel erscheinen die Leibschmerzen episodenhaft, wobei die Krisen Stunden, Tage oder Wochen dauern können. Symptomarme Intervalle umfassen Zeiträume von einigen Tagen bis zu mehreren Jahren. Die Schmerzintensität kann unterschiedlich sein; im Vergleich mit der akuten Pankreatitis ist sie eher geringer. Verschieden wird das Verhältnis zur Nahrungsaufnahme angegeben: In den meisten Fällen wird durch eine Mahlzeit eine Schmerzzunahme hervorgerufen; andere Patienten berichten von einem geringen Einfluß oder von einer Schmerzlinderung. Das gleiche bezieht sich auch auf den Genuß von alkoholischen Getränken in Fällen mit alkoholischer Pankreatitis. Typisch soll die Exazerbation der Schmerzen 12-48 h nach einem Alkoholexzeß sein. Oftmals berichten die Betroffenen über eine Linderung der Beschwerden bei Einnahme einer vorgebeugten Körperhaltung, wobei die Arme an den Bauch gedrückt werden (Abb. 8.8), sowie bei Applikation von Wärme.

Die Entstehungsweise der Schmerzen konnte bisher nicht eindeutig geklärt werden. Einige Befunde sprechen dafür, daß Schmerzen mit der Speichelsekretion verknüpft sind. Dies könnte verständlich machen, warum nach 5- bis 10jährigem Krankheitsverlauf mit dem Verlust des exokrinen Drüsengewebes die Beschwerden geringer werden oder verschwinden. Die "schmerzstillende“ Wirkung einer Pankreasenzymsubstitution würde auf eine sekretionshemmende Wirkung dieser Präparate zurückzuführen sein.

Eine weitere Beschwerde ist die Gewichtsabnahme. Sie wird vor allem bei fortgeschrittenen Erkrankungen durch die Maldigestion infolge des Mangels an Verdauungsenzymen erklärbar. Wichtiger ist jedoch die verminderte Nahrungsaufnahme, da die Patienten wegen der Schmerzen nichts mehr essen mö-

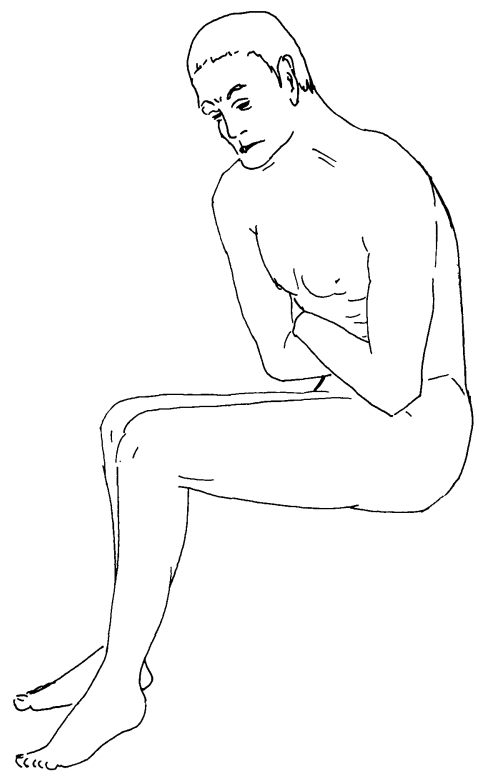

Abb. 8.8. Körperhaltung zur Linderung der Leibschmerzen bei chronischer Pankreatitis. Durch das Vorbeugen des Oberkörpers und das Eindrücken des Bauches mit den verschränkten Armen erreichen viele Patienten eine Besserung ihrer Beschwerden. In diesen Fällen ist die Diagnose bereits mit einem Blick zu stellen 
gen oder den Appetit verlieren. Bei Alkoholikern kann darüber hinaus eine Fehlernährung eine Rolle spielen.

Erkrankungen im Pankreaskopfbereich sind bei einem Teil der Betroffenen mit zumeist intermittierend auftretender Gelbsucht verknüpft. Sie erklärt sich durch die Kompression des Ductus choledochus bei seinem intrapankreatischen Teil.

Die Insuffizienz der exokrinen und endokrinen Drüsenfunktionen wird als Spätfolge der chronischen Pankreatitis beobachtet. Wegen der großen Reservekapazität des exokrinen Pankreas ist mit einer Maldigestion erst nach dem Verlust von etwa $90 \%$ der funktionsfähigen Drüsenzellen zu rechnen. Am empfindlichsten wird die Fettverdauung betroffen; es resultieren eine Malabsorption der Fette und fettlöslichen Vitamine sowie eine Steatorrhö (bis zu $100 \mathrm{~g}$ Fett täglich). Begleitend ist in der Regel eine Kreatorrhö. Die Patienten setzen entsprechend voluminöse Fettstühle ab, deren Gewicht im Durchschnitt $250 \mathrm{~g} /$ Tag übersteigt. Seltene Folgen sind Hypalbuminämie, Hautpigmentierungen oder Osteomalazie. Ein Diabetes mellitus als Folge der endokrinen Insuffizienz wird bei etwa $1 / 3$ der Fälle mit kalzifizierender Pankreatitis gesehen; ein weiteres Drittel der Patienten zeigt einen latenten Diabetes mellitus. Die Therapie jener Fälle kann insofern schwierig sein, als - wohl infolge des gleichzeitigen Mangels an gegenregulatorisch wirksamem Glukagon - eine erhöhte Insulinempfindlichkeit mit Neigung zu bedrohlichen Hypoglykämien besteht; weiter halten die Patienten wegen der Schmerzen oft nur unzuverlässig eine Diät ein. Die Häufigkeit diabetischer Spätkomplikationen soll geringer sein.

In Fällen mit schmerzloser Entzündung (ca. 10\%) wird die Pankreaserkrankung leicht übersehen. Führend sind hier evtl. Komplikationen wie z. B. ein Diabetes mellitus.

Bei der körperlichen Untersuchung zeigen Patienten mit fortgeschrittener chronischer Pankreatitis oftmals eine Unterernährung. Hautpigmentierungen als Folgen der Maldigestion sind seltene Befunde. Manchmal besteht eine braune Hautverfärbung über dem Pankreas infolge chronischer Wärmeanwendungen („Melanoderm“). Die Tastuntersuchung des Bauches bzw. des Pankreas erbringt in der Regel keine pathologischen Befunde; allenfalls lassen sich große Zysten palpieren. Als weiteres Hautzeichen sei die Gelbsucht erwähnt.

\section{Komplikationen}

Das Schicksal der Patienten wird auch durch das Auftreten von Komplikationen bestimmt. Ein häufiger Befund sind Pseudozysten, die im Gegensatz zu den Pseudozysten bei akuter Pankreatitis keine Rückbildungstendenz zeigen. Man beobachtet sie in unterschiedlicher Größe und Zahl. Eine häufige Lokalisation ist die Bursa omentalis; selten kann auch intrathorakal eine Zyste gefunden werden. Beschwerden entstehen durch die mechanische Verdrängung der benachbarten Organe (Magen, Duodenum, Kolon, Pfortadergefäße, Gallenwege etc.); bedrohlich werden Zystenblutungen und Infektionen. Kommt es zur Perforation der Zysten in die Bauchhöhle, so wird dies als Aszites bzw. Peritonitis erkennbar. Perforationen in den Gastrointestinaltrakt bringen dagegen eine Heilung. An die Existenz von Pseudozysten sollte man bei protrahiert verlau- 
fenden Krankheitsepisoden mit Schmerzen, Fieber oder erhöhten Aktivitäten von Amylase und Lipase im Serum denken; Folgen der mechanischen Verdrängung zeigen sich gegebenenfalls durch Subileuserscheinungen mit Übelkeit, Erbrechen oder durch Gelbsucht. Aszites, Pleura- oder Perikardergüsse entstehen durch pathologische Verbindungen der Körperhöhlen mit dem Pankreasgangsystem, wobei - wie erwähnt - Pseudozysten den Weg bilden können; eine andere Ursache sind Behinderungen des Lymphabflusses bei gleichzeitiger Hypalbuminämie und Pfortaderhochdruck. Im Gegensatz zu hepatischem Aszites sind die Eiweiß- und Pankreasenzymgehalte hoch. Gastrointestinale Blutungen erfolgen aus Varizen bei regionalem Pfortaderhochdruck infolge Kompression oder Thrombose der V. lienalis (Therapie: Splenektomie), aus dem Pankreasgang durch Wirsungorrhagie oder aus peptischen Geschwüren; nach verschiedenen Angaben wird diese Komplikation bei ca. 10\% der Patienten angetroffen. Weitere mögliche Erkrankungen sind die Leberzirrhose durch chronischen Alkoholismus oder sekundär bei chronischer Cholestase/Cholangitis sowie Gallensteine. Nach den neueren pathogenetischen Vorstellungen sollen diese - im Gegensatz zur akuten Pankreatitis - keine Bedeutung für die Entstehung der chronischen Bauchspeicheldrüsenentzündung besitzen. Möglicherweise wird die Bildung von Choledochussteinen (Häufigkeit bis 17\%) durch eine Galleabflußbehinderung begünstigt. Chronische Bauchspeicheldrüsenentzündungen sollen zur malignen Entartung neigen.

Diagnostik. Aus verschiedenen Gründen kann die Erkennung einer chronischen Pankreatitis schwierig sein: 1. Wenn die führenden Symptome, insbesondere Leibschmerzen, nicht richtig gedeutet werden. 2. Wenn in den frühen Stadien objektivierbare Veränderungen fehlen. Für die Bestätigung der Diagnose muß man in der Regel sowohl morphologische Veränderungen als auch Funktionseinschränkungen bewerten. Keine der Methoden kann in jedem Fall die Krankheit anzeigen. Man wird deshalb in unklaren Fällen verschiedene Untersuchungsverfahren einsetzen müssen. In der Übersicht sind die gebräuchlichen Tests dargestellt:

Klinisch-chemische Tests, Funktionstests

- Amylase-, Lipaseaktivität in den verschiedenen Körperflüssigkeiten; Blutsenkung; Blutbild; Kalzium; Blutzucker

- Funktionsprüfungen des exokrinen Pankreas: Stuhlfettausscheidung; Stuhlgewicht; Chymotrypsingehalt im Stuhl; Pancreolauryltest; NBT-PABA-Test; Sekretin-Pankreozymin-Test

- Funktionsprüfungen des endokrinen Pankreas: Glukosetoleranztest

Morphologisch orientierte Untersuchungsmethoden

- Röntgenaufnahme des Pankreas

- Sonographie

- Computertomographie

- Endoskopisch retrograde Cholangio-Pankreatographie

- Intravenöse Cholangiographie

- Sonstige: Thoraxröntgenaufnahme; Magen-Darmpassage/hypotone Duodenographie; Angiographie; Szintigraphie; supragastrische Pankreaskopie; endoskopische Sonographie

Als bestes Verfahren gilt traditionell der Sekretin-Pankreozymin-Test (s. 8.4.2). Er ist jedoch methodisch aufwendig und liefert zuverlässige Resultate, wenn er 
Abb. 8.9. Chronisch kalzifizierende Pankreatitis. Auf der Röntgenübersichtsaufnahme der Bauchspeicheldrüse erscheinen die Verkalkungen als helle Flecken

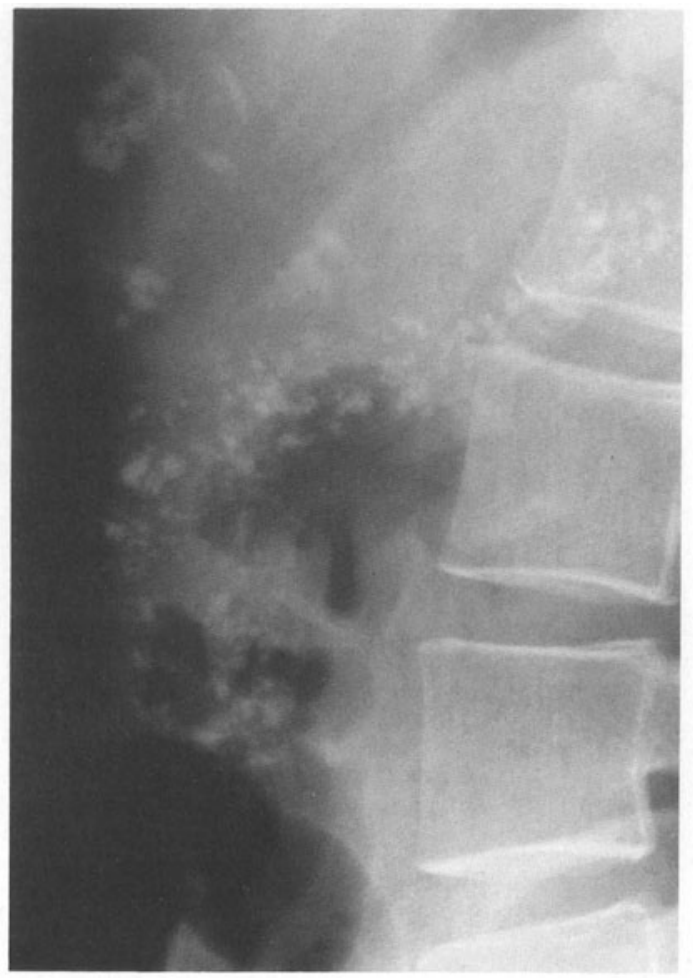

regelmäßig von geübtem Personal durchgeführt wird. Ein pathologisches Ergebnis ist zu erwarten, wenn etwa $90 \%$ des funktionsfähigen Drüsengewebes ausgefallen sind. Normale Ergebnisse wurden - allerdings selten - z. B. bei Patienten, die Pankreasverkalkungen oder Gangveränderungen als sichere Zeichen der chronischen Pankreatitis aufwiesen, gefunden. Es hat sich bewährt, zunächst einfacher durchführbare Tests einzusetzen. Als „Basisdiagnostik“ bei Verdacht auf chronische Pankreatitis können folgende Untersuchungen dienen: Stuhlgewicht, Chymotrypsin im Stuhl, Pancreolauryl-Test (oder: NBT-PABATest), Glukosebelastung (s. 8.4).

Zur morphologischen Diagnostik empfehlen sich zuerst die Röntgenaufnahmen des Pankreas (Frage: Verkalkungen) und die Sonographie (Beurteilung der Pankreasgröße, -form, -binnenstruktur; Zysten; Gallenwege; Aszites). Pankreasverkalkungen lassen sich bei optimaler Röntgentechnik in etwa der Hälfte der Fälle nachweisen (Abb. 8.9); im Sonogramm gelingt der Nachweis größerer Konkremente (Abb. 8.10). In unklaren Fällen ist als nächste, aufwendigere Untersuchung die Computertomographie (CT) geeignet. Bei 75-90\% der Patienten erbringt sie den Befund einer chronischen Pankreatitis, wobei in annähernd $100 \%$ die Diagnose richtig gestellt werden kann. Sie übertrifft damit die Leistungsfähigkeit der Sonographie um etwa $10-30 \%$. Neben den Größenveränderungen der Drüse können das Gangbild und die Binnenstruktur unabhängig von meteoristischen Darmschlingen beurteilt werden (Abb. 8.11). Beispielsweise werden Steine erkennbar, die im Nativröntgenbild nicht dargestellt werden. 

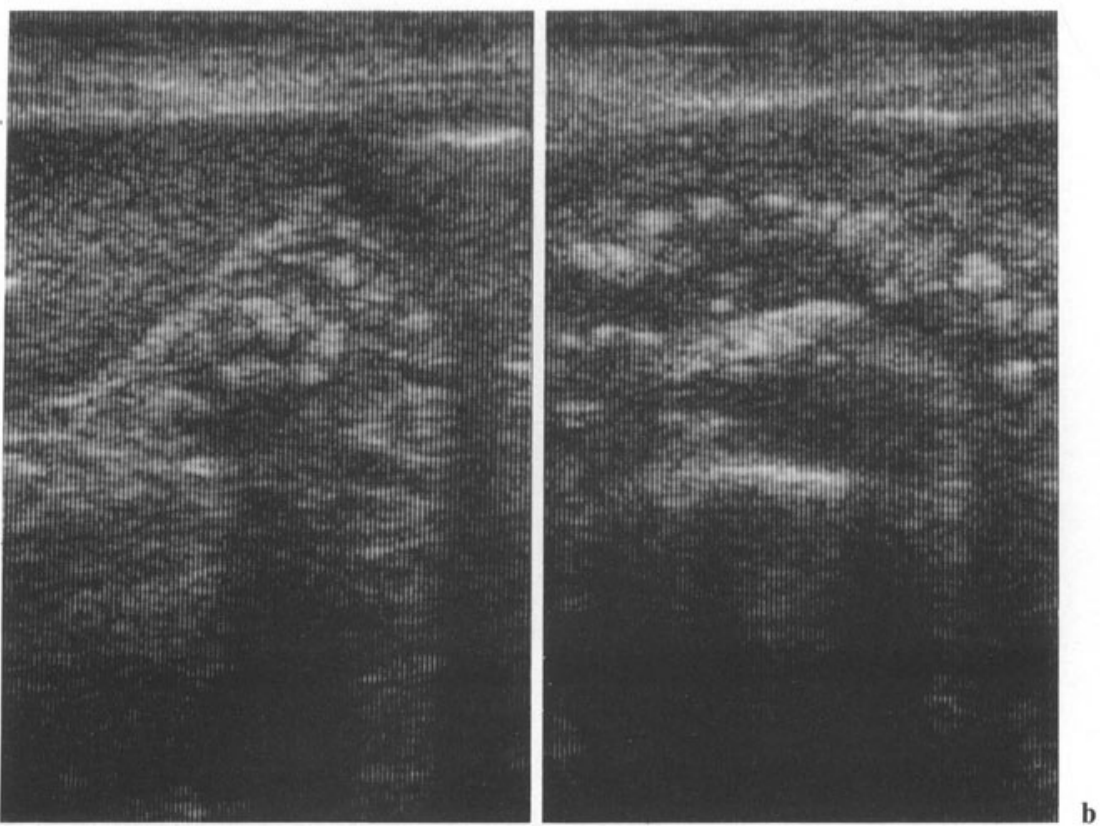

Abb. 8.10a, b. Chronisch kalzifizierende Pankreatitis. Sonogramm des Pankreaskopfes (a) und des Pankreaskörpers/-schwanzes (b). Das Pankreas ist verdickt. Die Verkalkungen erscheinen als weiße Flecken im Parenchym, die im Kopfbereich zu einem Schallauslöschungsphänomen führen

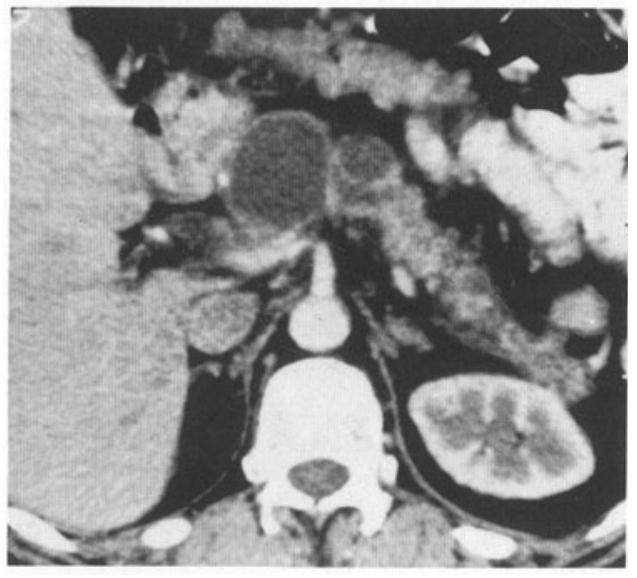

Abb. 8.11. Chronische Pankreatitis mit Ausbildung von Pseudozysten im Bereich des Pankreaskopfes (Computertomogramm)

Die endoskopische retrograde Pankreatographie (ERP) dient der Darstellung des Gangsystems. Im Laufe der chronischen Bauchspeicheldrüsenentzündung können in etwa 70-90\% der Fälle charakteristische Veränderungen beobachtet werden (Abb. 8.12). Sie betreffen sowohl den Hauptgang als auch die Seitenäste. Von geringen Veränderungen spricht man, wenn mehr als 3 Seitenäste verändert sind. Mäßiggradige Veränderungen werden durch pathologische Befun- 
Abb. 8.12. Schwergradige Gangveränderungen bei chronischer Pankreatitis

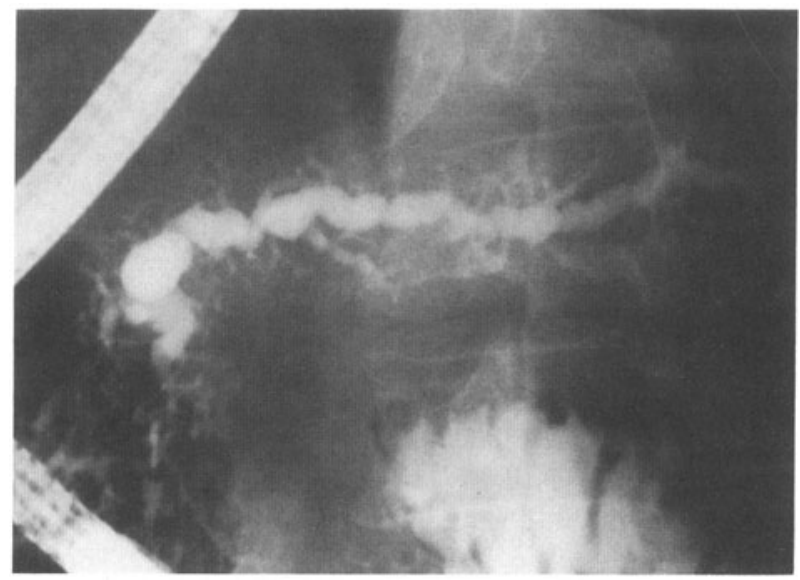

de am Hauptgang und mehr als 3 Seitenästen ausgewiesen. Schwere Erkrankungen zeigen sich durch zusätzliche Befunde wie Füllungsdefekte, Stenosen, Höhlungen (Zysten, Pseudozysten, Abszesse) sowie massive Erweiterungen $(1 \mathrm{~cm})$ und Unregelmäßigkeiten des Gangsystems. In etwa 10\% der Fälle ist das Pankreas nur zum kleineren Teil sichtbar verändert (,segmentale Pankreatitis“, besonders im Schwanzbereich); eine Sonderform ist die „Rinnenpankreatitis“, welche zwischen Pankreaskopf, Duodenum und Ductus choledochus auftritt und zur Duodenalstenose führen kann. Sollten am Ende noch diagnostische Unsicherheiten bestehen, so kann dies als Indikation für den erwähnten SekretinPankreozymin-Test angesehen werden. Die übrigen in der Übersicht S. 486 dar gestellten Methoden werden nur selten eingesetzt.

In der Literatur werden bei vergleichenden Untersuchungen die diagnostischen Qualitäten der einzelnen Verfahren unterschiedlich bewertet. Die Ursachen dürften in der zumeist kleinen Patientenzahl, in der unterschiedlichen Technik sowie in dem Fehlen einer eindeutigen Referenzmethode zu suchen sein.

Differentialdiagnose. Geht man vom Beschwerdebild - Leibschmerzen, Durchfall, Gewichtsabnahme etc. - aus, so muß eine Vielzahl von Krankheiten erwogen werden. Häufige Fehldiagnosen sind „Gastritis“, „Cholezystopathie“, „Reizmagen/Reizdarm“. Wenn gleichzeitig die exkretorischen Bauchspeicheldrüsenenzyme erhöht sind, dann kommt auch eine akute Pankreatitis in Betracht. Die Entscheidung für diese Diagnose oder für den akuten Schub einer chronischen Pankreatitis kann erhebliche Schwierigkeiten bereiten, insbesondere bei Alkoholikern oder bei Fehlen sonstiger durch bildgebende Verfahren oder Funktionstests objektivierbarer Veränderungen. Ein erhebliches Problem kann die Abgrenzung eines bösartigen Pankreastumors bedeuten (s. 8.7). Wertvolle diagnostische Informationen lassen sich durch die histologische bzw. zytologische Untersuchung von sonographisch oder computertomographisch gezielt entnommenem Material gewinnen. Weitere, weniger zuverlässige Möglichkeiten sind die Bestimmung der Tumorantigene (CA 19-9; CEA) im Blut oder im Duodenalsaft (s. 8.7). 
Eine exkretorische Pankreasinsuffizienz wird auch bei der Hämochromatose (s. 6.17) sowie bei der Mukoviszidose (Synonym: zystische Fibrose) beobachtet. Diese häufige angeborene Stoffwechselerkrankung ist durch eine gestörte Funktion der exokrinen Drüsen gekennzeichnet. Sie bilden einen zähflüssigen, eiweißreichen, die Ausführungsgänge verstopfenden Schleim. Als Folgen resultieren zystische und fibrotische Umwandlungen jener Drüsen. Durch das Fehlen des Schleims neigen die Patienten zu Bronchialerkrankungen sowie zur Speicheldrüsen- bzw. Pankreasinsuffizienz mit Maldigestion. Etwa die Hälfte der Patienten erreicht das Erwachsenenalter. Die Diagnose wird am besten anhand des erhöhten Gehalts von Kochsalz im Schweiß gestellt (Pilocarpin-Iontophorese). Die Therapie ist gegen die Symptome gerichtet, wobei Mukolytika, Antibiotika, Enzymsubstitutionspräparate, Vitamine und besser resorbierbare Diäten eingesetzt werden.

Therapie. Die konservative Behandlung der chronischen Pankreatitis ist auf die Linderung der Schmerzen und auf den Ausgleich der Drüseninsuffizienz gerichtet. Daneben treten diätetische Maßnahmen, vor allem die Alkoholabstinenz (!) und die Verordnung kleiner häufiger Mahlzeiten mit einem auf ca. $25 \%$ begrenzten Fettgehalt; bei Fällen mit ausgeprägter Steatorrhö ist die Verwendung mittelkettiger Triglyzeride (Ceres-Magarine, -Speiseöl; Hersteller: Margarine Union, Hamburg) sinnvoll, weil sie direkt absorbiert werden können. Die Proteinzufuhr sollte etwa $100 \mathrm{~g} /$ Tag betragen; die Menge der Kohlenhydrate muß am Kalorienbedarf und an der Stoffwechselsituation (Diabetes mellitus?) bemessen werden (s. unten).

In der Praxis ist die Schmerzbekämpfung das größte Problem. Leichtere Krisen lassen sich durch Analgetika mit peripherer Wirkung (Azetylsalizylsäure, Paracetamol etc.), die vor den Mahlzeiten gegeben werden, behandeln. Von einigen Autoren wird auch ein schmerzlindernder Effekt der Enzymsubstitutionspräparate mitgeteilt; eine endgültige Stellungnahme ist hierzu derzeit nicht möglich. In schweren Fällen kommen stark wirksame, zentral angreifende Schmerzmittel in Betracht, insbesondere auch Opiate. Wegen der Suchtgefahr wird man sie jedoch zurückhaltend einsetzen. Weitere Maßnahmen sind die Nervenblockade über einen Periduralkatheter und die Injektion von Alkohol in das Ganglion coeliacum. Bei einem Teil der Patienten sind als letzte Möglichkeit chirurgische Eingriffe indiziert. Je nach dem pathologisch-anatomischen Befund werden Resektionen oder Drainageverfahren eingesetzt. Weitere Indikationen für chirurgische Maßnahmen sind Gallenblasen- und Gallengangsteine sowie Komplikationen wie Aszites, Pseudozysten oder Kompressionserscheinungen an benachbarten Organen. Entschließt man sich wegen der Schmerzen zu einer Operation, so sollte man sich darüber im klaren sein, daß nach 5-10 Jahren die Schmerzen ohnehin von selbst geringer werden oder verschwinden. In einer kritischen Untersuchung wurde kürzlich der Wert chirurgischer Maßnahmen für die Linderung der Schmerzen angezweifelt [1]. Nach geltender Meinung sind sie bei Alkoholikern, die ihren Alkoholmißbrauch fortsetzen, in jedem Fall sinnlos.

Eine Enzymsubstitution ist bei den Patienten, die täglich mehr als ca. $10-15 \mathrm{~g}$ Fett mit dem Stuhl ausscheiden, nötig. Weitere Indikationen sind 
Schmerzen (s. oben) und sonstige Mißempfindungen im Oberbauch, Durchfälle oder eine Gewichtsabnahme. Zur Behandlung sind Pankreatinpräparate in hoher Dosierung (d. h. 5-10 g täglich), zu den Mahlzeiten genommen, geeignet. Zubereitungen als Granulat besitzen den Vorteil der guten Verfügbarkeit bei den Verdauungsvorgängen. Es muß jedoch mit einer Inaktivierung durch das saure Milieu im Magen gerechnet werden. Günstig wird deshalb die gleichzeitige Gabe von Histamin- $\mathrm{H}_{2}$-Blockern (Cimetidin, Ranitidin) oder aluminiumhydroxidhaltiger Antazida bewertet. Gleichwertig dürften neuere mikroverkapselte Präparate sein, die bei schwach saurem Milieu freigegeben werden und keine säurehemmende Begleittherapie benötigen. Der Erfolg läßt sich an einer Besserung der Beschwerden sowie an einer Normalisierung der objektivierbaren Parameter (Stuhlfett, Stuhlgewicht) und schließlich an einer Gewichtszunahme ermessen. Therapieversager sind am häufigsten durch eine zu niedrige Dosierung oder die ungenügende Mitarbeit des Patienten bedingt. Gallensäurehaltige Enzymsubstitutionspräparate können zur chologenen Diarrhö führen; sie werden deshalb weniger empfohlen.

Die endokrine Pankreasinsuffizienz mit manifestem Diabetes mellitus wird nach den üblichen Regeln durch Diät und Insulin behandelt. Orale Antidiabetika sind zumeist nicht ausreichend wirksam.

Patienten mit gestörter Fettverdauung weisen evtl. einen Mangel an fettlöslichen Vitaminen auf. In diesen Fällen ist die parenterale Gabe der Vitamine D, E, K, A sinnvoll.

\subsection{Geschwülste der Bauchspeicheldrüse}

Neubildungen werden sowohl bei exkretorischen als auch bei endokrinen Bauchspeicheldrüsengeweben beobachtet. Gutartige Geschwülste können vom Azinusepithel (Adenom, Karzinoid), vom Gangepithel (Papillom, Zystadenom, Teratom) oder von den Zwischengeweben (Lipom, Fibrom, Hämangion etc.) ausgehen. Sie sind sehr selten und werden meistens zufällig bzw. bei Sektionen entdeckt. Von den bösartigen Geschwülsten des exokrinen Pankreas sind die Karzinome klinisch am bedeutsamsten; Sarkome sind dagegen im Vergleich seltener. Beide Tumorklassen manifestieren sich zumeist in einem späten, inkurablen Stadium. Neubildungen der endokrinen Bauchspeicheldrüsengewebe bilden u. U. im Übermaß einzelne oder mehrere Substanzen mit Hormoneigenschaften. Diese können zu spezifischen Wirkungen führen, an denen die Geschwülste gegebenenfalls frühzeitig zu erkennen sind.

\subsubsection{Bauchspeicheldrüsenkarzinom}

Bauchspeicheldrüsenkarzinome stehen nach dem Dickdarm- und Magenkarzinom an der 3. Stelle bei den bösartigen Geschwülsten der gastrointestinalen Organe. Im Sektionsgut sind etwa 5\% der Erwachsenen - bei ansteigender Tendenz - betroffen. Männer erkranken 2mal häufiger als Frauen. Das Pankreaskarzinom wird in jedem Lebensalter beobachtet; bevorzugt wird jedoch das 6 . 
und 7. Lebensjahrzehnt. Das histologische Erscheinungsbild der Geschwülste ist überaus vielgestaltig. Zumeist werden sie als Adenokarzinome klassifiziert. Die häufigste Lokalisation ist der Bauchspeicheldrüsenkopf (etwa $2 / 3$ der Fälle); es folgen der Körper (etwa 1/4 der Fälle) und der Schwanz. Absiedelungen erscheinen bevorzugt in der Umgebung des Pankreas bzw. in den regionalen Lymphknoten sowie in der Leber. Als Risikofaktoren werden die chronische kalzifizierende Pankreatitis, ein Verzehr von tierischen Fetten, Zigarettenrauchen sowie Kaffeegenuß diskutiert. Ein vermehrtes Vorkommen der Erkrankung wurde bei Metallarbeitern sowie bei Personen, die Kontakt zu Benzidin, $\beta$-Naphthylamin oder alkylierenden Zytostatika hatten, festgestellt.

Klinik. Die häufigsten Beschwerden sind Gewichtsabnahme, Leibschmerzen, die zumeist unabhängig vom Essen sind und sich oftmals beim Vorbeugen etc. bessern, und Gelbsucht. Seltener wird über Übelkeit, Erbrechen, Flatulenz, Stuhlunregelmäßigkeiten oder Juckreiz geklagt. Es handelt sich hierbei um die Symptome bei fortgeschrittener Erkrankung. Patienten mit Pankreaskarzinomen in frühen, heilbaren Stadien sind fast ausnahmslos beschwerdefrei. Die gleichen Überlegungen gelten auch für Befunde bei der körperlichen Untersuchung. In fortgeschrittenen Fällen findet man einen tastbaren Pankreastumor, eine Lebervergrößerung, eine - oftmals vom Patienten übersehene - Gelbsucht, eine tastbare Gallenblase (Courvoisier-Zeichen) oder Aszites. Hinweise können auch eine Thrombophlebitis saltans sowie eine Splenomegalie oder ein systolisches Gefäßgeräusch im linken Oberbauch infolge der Verlegung der V. bzw. A. lienalis geben.

Der weitere Krankheitsverlauf ist durch die rasch zunehmende Tumorkachexie gekennzeichnet. Nur wenige Patienten leben nach Stellung der Diagnose länger als $1 \mathrm{Jahr}$.

Diagnostik. Die frühzeitige Erkennung des Pankreaskarzinoms ist - ähnlich wie beim Kolon- und Magenkarzinom - eine der größten und schwierigsten Aufgaben in der Gastroenterologie. Anamnese und Befund können hier nur einen geringen Beitrag leisten: Jede unklare Bauchbeschwerde, jede Thrombophlebitis oder jeder neu aufgetretene insulinpflichtige Diabetes mellitus bei älteren Personen sollte an diese Krankheit denken lassen. Objektivierbare Veränderungen sind erst in den fortgeschrittenen Stadien der Tumorerkrankung feststellbar. Eine Ausnahme bildet allenfalls eine kleine Geschwulst nahe dem intrapankreatischen Anteil des Ductus choledochus, die sich durch die Symptome der Galleabflußbehinderung anzeigt.

Bei den klinisch-chemischen Tests finden Tumorantigene besonderes Interesse. Von den verschiedenen untersuchten Markern sind die Konzentrationen von karzinoembryonalem Antigen und CA 19-9 häufiger (bis 30\% bzw. 90\% der Fälle) im Blut und im Bauchspeichel von Pankreaskarzinompatienten erhöht gemessen worden; es handelte sich jeweils um fortgeschrittene Fälle. Unklar ist, inwieweit diese Tests frühe Krankheitsstadien anzeigen können. Weitere klinisch-chemische Parameter sind die Blutsenkungsreaktion und - bei Verschluß der extrahepatischen Gallenwege - die Parameter der Cholestase (Bilirubin, alkalische Phosphatase, $\gamma$-Glutamyltranspeptidase, Transaminasen im Serum). 


\begin{abstract}
Abb. 8.13. Pankreaskopfkarzinom. Sonographisches Schnittbild am Leberhilus. Rechts erkennt man die Geschwulst als rundliches, echoarmes, angedeutet inhomogen strukturiertes Gebilde. Sie hat zu einer totalen Abflußbehinderung der Galle geführt; als Folge erscheint der Ductus choledochus auf über $1,5 \mathrm{~cm}$ erweitert (links). Der Pfeil weist auf den Ort der Gallengangsverlegung. $L$ Leber. - Gleichzeitig waren die intrahepatischen Gallenwege erweitert und die Gallenblase stark vergrößert (Courvoisier-Zeichen). Die Diagnose ließ sich anhand von Material sichern, das durch sonographisch geführte Feinnadelpunktion gewonnen worden war
\end{abstract}

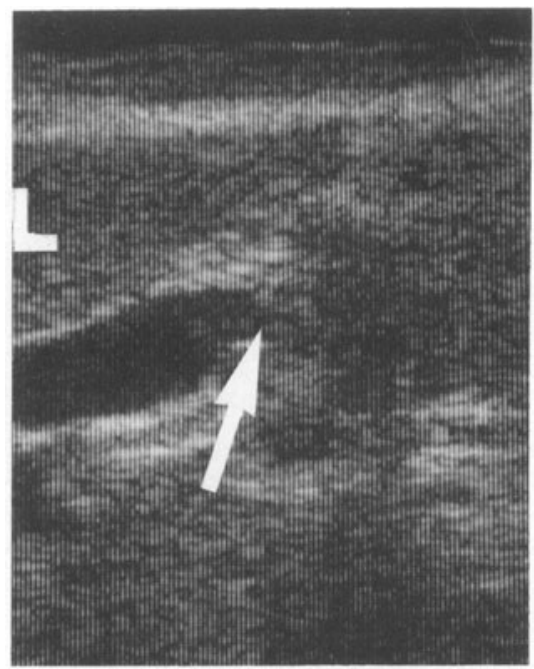

Unter den bildgebenden Verfahren steht die Sonographie an erster Stelle. Sie erlaubt in etwa 90\% der Fälle eine Darstellung des Pankreas, wobei am besten Kopf und Körper beurteilbar sind. Geschwülste zeigen sich durch eine Veränderung der Parenchymstruktur, durch eine Verdickung des Organs, durch eine Weitstellung des distal gelegenen Gangs, durch eine Erweiterung der extrahepatischen Gallenwege und -blase oder durch Metastasen in der Leber (Abb. 8.13). Zur weiteren Klärung kann mittels Feinnadel unter sonographischer Führung Material für die histologische und zytologische Untersuchung entnommen werden. In den Fällen, in denen die Sonographie kein befriedigendes Ergebnis bringt (Fettsucht, Meteorismus etc.), ist als aufwendiges Verfahren die Computertomographie indiziert. Sie erlaubt in jedem Fall eine Darstellung der Bauchspeicheldrüse, insbesondere auch der Schwanzregion. Im Vergleich mit der Sonographie wird der diagnostische Wert dieser Methode größer eingeschätzt. Beide Verfahren sind jedoch nicht in der Lage, Frühkarzinome mit Durchmessern unter $0,5-1 \mathrm{~cm}$ darzustellen.

Als nächster diagnostischer Schritt kommt gegebenenfalls die endoskopische retrograde Cholangiopankreatographie $(E R C P)$ in Betracht. Bösartige Geschwülste werden hier anhand der Veränderungen des Pankreas- und Gallengangsystems dargestellt (Abb. 8.14). Beobachtet werden Gangverschlüsse oder -stenosen, bei welchen der distale Ganganteil erweitert erscheint; in anderen Fällen findet man langstreckige Gangverjüngungen ohne prästenotische Ektasie oder - als Folge von Gewebezerfall höhlenartige Erweiterungen. Papillennahe Karzinome zeigen sich durch eine gleichzeitige prästenotische Dilatation des Pankreas- und Gallengangs (Abb. 8.15). Oftmals offenbart sich die Geschwulst bereits durch das Aussehen der Papille (Vergrößerung, Diskolorierung, Umbauzeichen). Bei den - fortgeschrittenen - Fällen, in denen die Diagnose zu sichern war, fanden sich bei verschiedenen systematischen Studien in ca. 90\% der Fälle Abweichungen. Wertvoll ist auch die Möglichkeit, hierbei Bauchspeichel 

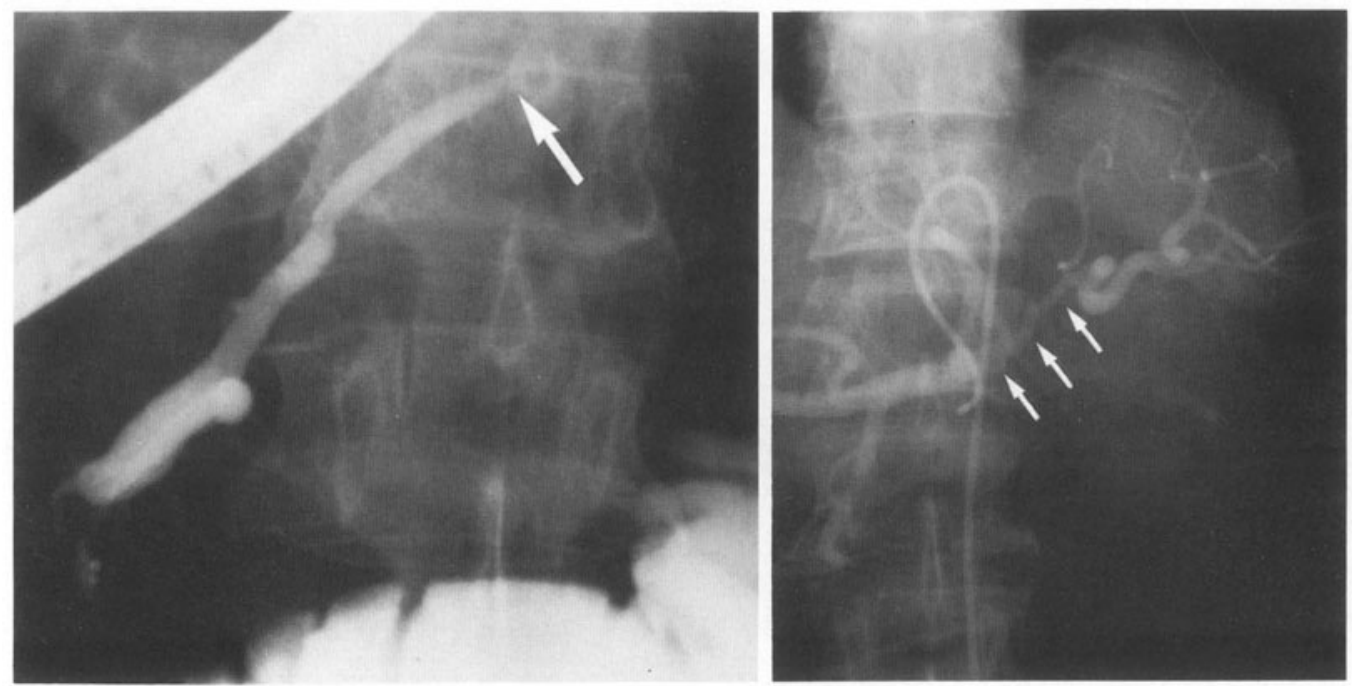

a Abb. 8.14a, b. Bösartige Geschwulst im Bereich des Bauchspeicheldrüsenkörpers. a Bei der endoskopisch retrograden Pankreatographie war ein Kontrastmittelstop aufgefallen (Pfeil). b In der Zöliakographie zeigte sich in diesem Bereich eine Stenose der A. lienalis (kleine Pfeile). Im Sonogramm und Computertomogramm fanden sich nur diskrete Veränderungen. - Die Diagnose eines Karzinoms wurde bei der Operation bestätigt

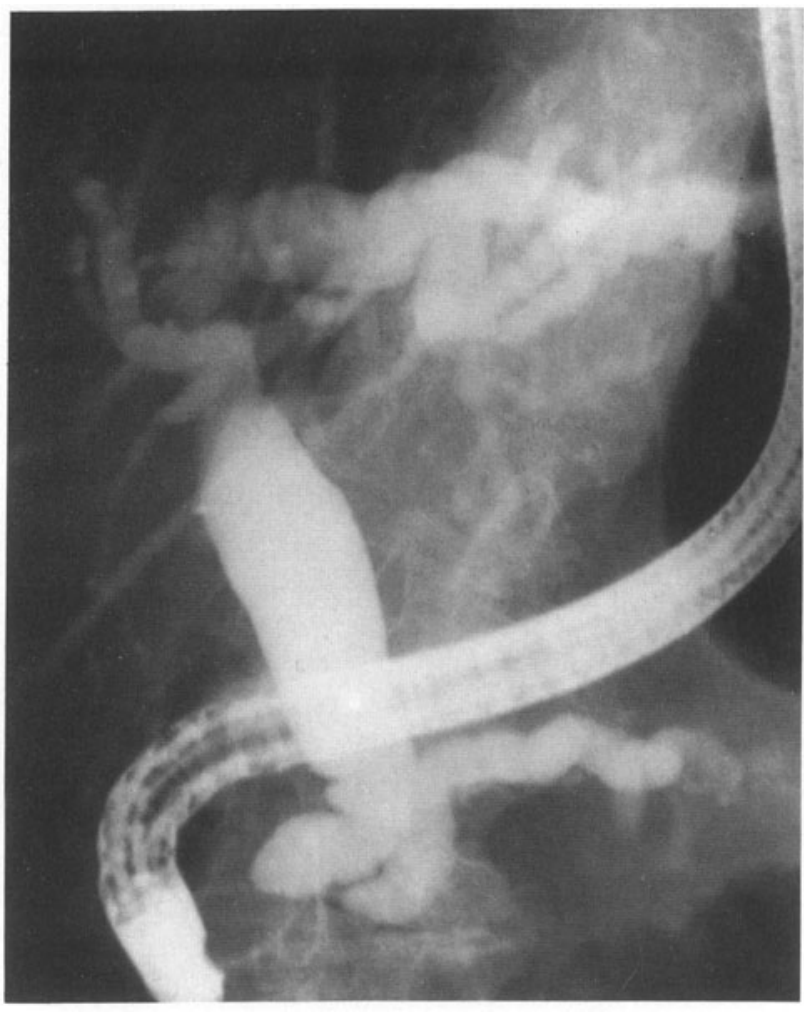

Abb. 8.15. Papillennahes Karzinom, das gleichzeitig zu einer Abflußbehinderung der Galle und des Bauchspeichels geführt hat. Bei der ERCP erkennt man als Folge eine Erweiterung beider Gangsysteme 
für klinisch-chemische Untersuchungen (Tumorantigene, Laktoferrin) oder die zytologische Beurteilung entnehmen zu können; hier wird man in etwa der Hälfte der Fälle ein hinweisendes Ergebnis erhalten. Weitere diagnostische Verfahren sind die Angiographie (Darstellung von abnormen Gefäßverläufen oder Gefäßen, s. Abb. 8.14), die Magen-Darm-Passage (Impressionen, Duodenalstenose), die perkutane transhepatische Cholangiographie (Darstellung der extrahepatischen Gallenwege bei Patienten mit Cholestase).

Differentialdiagnose. Geht man vom Beschwerdebild der Patienten - Gewichtsabnahme, Leibschmerzen, Gelbsucht, Stuhlunregelmäßigkeiten etc. aus, so kommt eine Vielzahl von Erkrankungen in Betracht. Entsprechend sind häufige Fehldiagnosen: Gastritis, Reizmagen, Reizdarm, Gallensteine, Hyperthyreose. Eine große Schwierigkeit kann auch die Abgrenzung der chronischen Pankreatitis sein. Neben dem klinischen Eindruck sind hier am besten die zytologischen und histologischen Untersuchungen von Punktionsmaterial sowie die Konzentration der Tumorantigene und die Veränderungen im Gangbild bei der retrograden Darstellung (ERP) geeignet. In seltenen Fällen ist die Klärung durch eine Probelaparotomie erforderlich.

Therapie. In den frühen Stadien ist die Resektion des Pankreaskarzinoms die Therapie der Wahl. Als Kriterien gelten die Verschieblichkeit der Geschwulst und eine fehlende Infiltration in den Retroperitonealraum bzw. in die regionalen Lymphknoten. Bei Erkrankungen des Pankreaskopfes (rechts der V. mesenterica superior) und -schwanzes ist eine Teilresektion des Pankreas möglich; in den übrigen Fällen wird die totale Pankreatektomie empfohlen (z. B. WhippleOperation).

Bei den meisten Patienten ist das Tumorleiden so weit fortgeschritten, daß lediglich palliative Maßnahmen in Frage kommen. Hierzu zählen bei Behinderung des Gallenflusses biliäre Drainagen, die auf endoskopisch-retrogradem oder perkutan-transhepatischem Weg eingesetzt werden. Nur ausnahmsweise sind palliative Operationen indiziert: Zur Beseitigung einer Duodenalstenose, zur Ableitung der Galle durch eine bilidigestive Anastomose oder zur Schmerzausschaltung. Für die Schmerzlinderung genügen meist Analgetika mit peripherem oder zentralem Angriffspunkt (Salizylate, Paracetamol bzw. Opiate). Knochenschmerzen sprechen manchmal gut auf antiphlogistisch wirkende Substanzen (Indometacin, Piroxicam etc.) an. Weitere Möglichkeiten sind die analgesierende Röntgenbestrahlung des Rückens oder die perkutane Blockade des Ganglion coeliacum durch Instillation von Alkohol; mit diesem Eingriff gelingt vielfach eine Linderung der Schmerzen für 1-2 Monate. Weder die Strahlentherapie noch die Chemotherapie (u. a. mit 5-Fluoruracil/Adriamycin/Mitomycin C) hat bisher einen Stellenwert in der Therapie des Pankreaskarzinoms gewinnen können: Die Wirkungen der Zytostatika (Ansprechraten ca. 25-30\%) erschienen im Vergleich mit den Nebenwirkungen gering; eine Verlängerung der Lebenserwartung war nicht festzustellen. 


\subsubsection{Hormonbildende Geschwiilste}

Im Gastrointestinaltrakt findet man eine Vielzahl von hormonbildenen Zellen. Aufgrund ihrer histochemischen Anfärbbarkeit werden sie auch als APUD-Zellen ( $a$ mine and/or amine precursor uptake and decarboxylation) bezeichnet. Viele Beobachtungen sprechen dafür, daß die Zellen trotz ihrer unterschiedlichen endokrinen, neurokrinen bzw. parakrinen Leistungen einen gemeinsamen Ursprung im embryonalen Ektoblast haben. Geschwülste dieser Zellen sind seltene Ereignisse: man schätzt die Zahl der jährlich in der Bundesrepublik Deutschland gefundenen Tumoren auf etwa 50. In den meisten Fällen sind sie in der Bauchspeicheldrüse lokalisiert. Im Gegensatz zu den übrigen Pankreastumoren können sie durch die übermäßige Hormonausschüttung auch in einem früheren Stdium zu Symptomen führen und diagnostiziert werden. Darüber hinaus werden evtl. mehrere Hormone ausgeschüttet, was auf den gemeinsamen Ursprung der APUD-Zellen hinweist. Die Diagnose läßt sich am besten anhand der Hormonkonzentration im Blut sichern. Der Wert der bildgebenden Verfahren ist eingeschränkt, wenn die Geschwülste wegen zu geringer Größe nicht darstellbar sind. Einen Überblick über wichtige hormonbildende $\mathrm{Ge}-$ schwülste zeigt Tabelle 8.3. Sie manifestieren sich durch weitgehend unspezifische Symptome und sollten vor allem bei differentialdiagnostischen Überlegungen einbezogen werden.

Das Zollinger-Ellison-Syndrom (Snyonym: Gastrinom) ist eine gastrinbildende Geschwulst. In der Mehrzahl der Fälle muß mit einem bösartigen Wachstum gerechnet werden. Die Lokalisation ist bei ca. $80 \%$ der Patienten im Pankreas; im übrigen finden sich die Tumoren im Duodenum, im Magen oder in benachbarten Geweben (Lymphknoten, Netz etc.). Bei ca. 1/4 der Fälle wird eine Kombination mit anderen endokrin aktiven Geschwülsten, insbesondere der Nebenschilddrüse, Nebennieren, Eierstöcke, Hirnanhangdrüse oder Schilddrüse im Sinne der dominant vererblichen multiplen endokrinen Adenomatose (MEA), Typ I, beobachtet (s. unten). Absiedelungen erfolgen vor allem in die regionalen Lymphknoten und in die Leber. Das histologische Bild der Ge-

Tabelle 8.3. Hormonbildende Geschwülste [6]

\begin{tabular}{|c|c|c|c|c|}
\hline Diagnose & Hormone & $\begin{array}{l}\text { Größe } \\
(\mathrm{cm})\end{array}$ & Symptome & $\begin{array}{l}\text { Maligne } \\
\text { Entartung } \\
(\%)\end{array}$ \\
\hline $\begin{array}{l}\text { Zollinger- } \\
\text { Ellison- } \\
\text { Syndrom }\end{array}$ & Gastrin & $0,5-4$ & $\begin{array}{l}\text { Peptische Geschwüre } \\
\text { des Magens und Duo- } \\
\text { denums, Durchfälle }\end{array}$ & $50-90$ \\
\hline $\begin{array}{l}\text { Verner- } \\
\text { Morrison- } \\
\text { Syndrom }\end{array}$ & $\begin{array}{l}\text { VIP; PHI; } \\
\text { Prosta- } \\
\text { glandin E }\end{array}$ & $2-7$ & $\begin{array}{l}\text { Sekretorische Diarrhö, } \\
\text { Hypokaliämie, } \\
\text { Hypochlorhydrie des Magens }\end{array}$ & ca. 40 \\
\hline Glukagonom & Glukagon & $4-10$ & $\begin{array}{l}\text { Nekrolytisches Erythem, } \\
\text { Diabetes mellitus }\end{array}$ & ca. 60 \\
\hline Insulinom & Insulin & $1-2$ & $\begin{array}{l}\text { Nüchternhypoglykämie, } \\
\text { Fettsucht }\end{array}$ & 10 \\
\hline
\end{tabular}


schwülste ist überaus vielgestaltig; am häufigsten handelt es sich um Adenome oder Adenokarzinome von Inselzellen.

Das klinische Bild läßt sich durch die übermäßige Ausschüttung von Gastrin erklären: Es entsteht eine Überproduktion von Salzsäure, die die Bildung von peptischen Geschwüren begünstigt. Erbrechen ist die Folge einer übermäBigen Bildung von Magensaft $(2-81 / 24 \mathrm{~h})$. Durchfälle werden durch direkte Wirkungen des Gastrins auf die Enterozyten sowie durch die ungenügende Neutralisierung des Magensaftes im Dünndarm erklärt; möglich ist darüber hinaus die zusätzliche Wirkung anderer Hormone, z. B. VIP, im Rahmen einer multiplen endokrinen Adenomatose. Im Vordergrund steht vor allem die Geschwürbildung, wobei diese oft mehrfach und an ungewöhnlichen Stellen (Speiseröhre, mittlerer Zwölffingerdarm) zu beobachten sind. Häufig kommt es zu Komplikationen: Perforation, Magenausgangsstenose, Blutung, Fistelbildung zum Dünn- oder Dickdarm. Eine Lebervergrößerung weist auf Metastasen hin. Die Diagnose wird evtl. übersehen, weil $\mathrm{H}_{2}$-Blocker gut wirksam sind. Viele Patienten erscheinen mit operiertem Magen.

Die Diagnose läßt sich in Anbetracht der vielen Patienten mit peptischen Geschwüren ohne Zollinger-Ellison-Syndrom allenfalls vermuten, wenn atypische oder therapieresistente Ulzera auftreten. Spezifische Symptome gibt es nicht. Entscheidend sind für die Sicherung der Diagnose der Serumgastrinspiegel, der bereits im Nüchternzustand stark erhöht ist, sowie die Ergebnisse der Magensekretionsanalyse, wo eine auf $15 \mathrm{mVal} / \mathrm{h}$ (operierter Magen: $5 \mathrm{mVal} / \mathrm{h}$ ) gesteigerte Nüchternsekretion von Salzsäure gemessen werden kann (s. 3.4). Nach Gabe von Pentagastrin wird eine geringere Zunahme der Säureausschüttung festgestellt. Zur weiteren Sicherung der Diagnose ist der Sekretintest geeignet: Bei Patienten mit Gastrinom steigt der Gastrinspiegel wenige Minuten nach Gabe von 2 E Sekretin/kg Körpergewicht stark an; Gesunde, Personen mit peptischen Ulzera oder Magenoperierte mit Antrumrest zeigen dagegen nur eine geringe oder keine Reaktion (vgl. 3.4). Für die Lokalisation des Tumors können die Sonographie, Computertomographie oder Angiographie verwendet werden, wobei kleinere Geschwülste evtl. übersehen werden. Eine weitere Möglichkeit bietet die Messung der Gastrinspiegel in gezielt auf transhepatischem Wege aus den Pankreasvenen entnommenen Blutproben. Besonders sorgfältig sollte auch nach Metastasen gesucht werden. Die endoskopisch retrograde Pankreatographie (ERP) ist für die Diagnostik weniger geeignet, da die Geschwülste keinen Anschluß an das Gangsystem besitzen. - Die differentialdiagnostischen Überlegungen wurden im Zusammenhang mit dem peptischen Ulkus dargestellt (s. 3.6). Es handelt sich vor allem um folgende Erkrankungen mit erhöhten Gastrinspiegeln: chronisch atrophische Gastritis; belassener Antrumrest nach Billroth-II-Operation; G-Zellhyperplasie; Nierenversagen; Zustand nach Vagotomie; Kurzdarmsyndrom. Die Abgrenzung ist am einfachsten mit dem Sekretintest möglich. Die Ziele jeder Therapie sind die Kontrolle des Tumors und der ungünstigen Gastrinwirkungen. Am einfachsten würde man diese durch die radikale Entfernung der Geschwulst erreichen. In den meisten Fällen ist die Resektion jedoch nicht möglich. Die Gastrinwirkungen lassen sich wirkungsvoll durch Histamin- $\mathrm{H}_{2}$-Blocker (1-3 g Cimetidin/Tag; 600-900 g Ranitidin/Tag) hemmen; noch zuverlässiger soll Omeprazol (bis $90 \mathrm{mg}$ ) angreifen. 
Die früher vielfach geübte totale Gastrektomie läßt sich damit bei den Personen, bei denen der Tumor wegen seiner Ausdehnung oder wegen Metastasierung nicht entfernen läßt, vermeiden. In einzelnen Fällen soll Streptozotocin $\left(500 \mathrm{mg} / \mathrm{m}^{2}\right.$, an 5 aufeinanderfolgenden Tagen) evtl. in Kombination mit 5-Fluoruracil zu einer Tumorverkleinerung geführt haben. Die Prognose der Gastrinome ist als günstig anzusehen, sofern die gastrinbedingten Komplikationen verhindert werden; Metastasen erscheinen weniger bedrohlich. Zur histologischen Sicherung der Diagnose und zur Beurteilung der Tumorgröße sollte auch bei ,inoperablen“ Fällen nach entsprechender Vorbereitung (Abheilung der Ulzera etc.) eine Probelaparotomie erfolgen.

Das Verner-Morrison-Syndrom (Synonym VIPom) ist durch die übermäßige Sekretion von vasoaktivem intestinalem Polypeptid (VIP) und Peptid Histidin Isoleuzin (PHI), 2 ähnlich wirksamen Eiweißkörpern, gekennzeichnet. Im Vordergrund des klinischen Bildes steht eine massive sekretorische Diarrhö, die auch nachts und bei Nahrungsentzug (mehr als $500 \mathrm{~g}$ Stuhl $/ 24 \mathrm{~h}$ ) persistiert. Weitere Befunde sind ein niedriger Blutdruck, eine Gewichtsabnahme, eine verminderte Bildung von Magensäure, eine geringe Hyperkalzämie sowie ein leichter Diabetes mellitus. Etwa 80\% der Geschwülste finden sich im Pankreas. Häufiger wurden auch Ganglioneuroblastome als Ursprungort gefunden. Die Diagnose wird anhand des erhöhten VIP-Spiegels im Serum gestellt. Differentialdiagnostisch kommen auch folgende Tumoren, die mit wäßrigen Durchfällen einhergehen können, in Betracht: medulläres Schilddrüsenkarzinom; Bronchialkarzinom; Karzinoid; Gastrinom. In diesen Fällen ist die VIP-Konzentration im Normbereich. Die Behandlung ist am besten durch die radikale Exzision der Geschwulst möglich. In den Fällen, in denen dies nicht möglich ist, kommt - bei Bedarf wiederholt - die medikamentöse Behandlung mit Streptozotocin $\left(500 \mathrm{mg} / \mathrm{m}^{2}\right.$, an 5 aufeinanderfolgenden Tagen) in Betracht, wobei der Erfolg am Absinken des VIP-Spiegels gemessen werden kann. Weitere Möglichkeiten sind Stoßbehandlungen mit Prednisolon $(50-60 \mathrm{mg} / \mathrm{Tag})$, Indometacin (bis $200 \mathrm{mg} / \mathrm{Tag}$ ) oder die Kombination von Lomustin $(2,5 \mathrm{mg} / \mathrm{kg}, 1$. Tag) und 5-Fluoruracil (30 mg/kg Körpergewicht, 2. -6. Tag) in 8 Zyklen bei 6wöchigem Abstand in Betracht.

Glukagonome leiten sich von den A-Zellen der Pankreasinseln ab. Durch die übermäßige Ausschüttung von Glukagon entsteht ein charakteristisches nekrolytisches migratorisches Erythem, das als makulopapulöse Rötung beginnt und schließlich infolge Absterbens der oberflächlichen Epidermis zur Blasenbildung führt. Die Abheilung erfolgt unter Hyperpigmentierung. Weitere Befunde sind ein leichter Diabetes mellitus, eine normochrome Anämie, die Neigung zu tiefen Venenthrombosen und Depressionen. Die Diagnose läßt sich durch den auf das 10- bis 20fache erhöhten Glukagonspiegel im Plasma sichern; in der Hälfte der Fälle ist auch pankreatisches Polypeptid (PP) erhöht. Die meisten Patienten haben langjährige Anamnesen mit entsprechend fortgeschrittenem Geschwulstwachstum, ehe die Diagnose gestellt wird. Mit den bildgebenden Verfahren läßt sich in der Regel der Tumor unschwer im Pankreas lokalisieren. Die Behandlung erfolgt - sofern dies möglich ist - durch chirurgische Resektion oder durch Streptozotocin, evtl. in Kombination mit Fluoruracil bzw. 
Doxorubicin. Die Erfolge sind hier unterschiedlich. Der Hautausschlag kann mit $200 \mathrm{mg}$ Zinksulfat/Tag behandelt werden.

Am häufigsten werden Geschwülste der B-Zellen mit vermehrter Sekretion von Insulin beobachtet (etwa $2 / 3$ der hormonbildenden Tumoren). Kennzeichnend für diese Insulinome sind Hypoglykämien mit Blutzuckerwerten unter $30 \mathrm{mg} / \mathrm{dl}$, die beispielsweise morgens vor dem Frühstück oder nachmittags beobachtet werden. Verstärkend wirken Alkoholgenuß oder körperliche Aktivität. Die Patienten klagen entsprechend über Heißhunger, Schwitzen, Herzklopfen, Tachykardie, Unruhe, Reizbarkeit oder Verwirrung. Am Ende kommt es zu zentralnervösen Erscheinungen mit Lähmungen, extrapyramidalen Störungen, epileptischen Reaktionen und hirnorganischem Psychosyndrom. Manche Patienten werden auch in Nervenkliniken behandelt, ehe die Diagnose gestellt wird. Da durch Kohlenhydratzufuhr die Beschwerden rasch zu bessern sind, haben viele Patienten ein erhebliches Übergewicht („Insulinmast“). Die Diagnose wird am einfachsten durch den Hungerversuch gestellt: Während einer maximalen Beobachtungszeit von $72 \mathrm{~h}$ wird als Folge der pathologischen Insulinausschüttung der Blutzucker erniedrigt, so daß ein pathologisches InsulinGlukose-Verhältnis entsteht. Bei den meisten Patienten muß wegen der Hypoglykämie der Test nach wenigen Stunden beendet werden. Weitere Möglichkeiten der Funktionsdiagnostik sind der Insulinsuppressionstest, bei dem die fehlende Unterdrückung der Insulin- bzw. C-Peptid-Bildung nach exogener Insulingabe bewertet wird, oder der Provokationstest der Insulinausschüttung durch Applikation von Glukagon ( $1 \mathrm{mg})$, Glukose $(0,5 \mathrm{mg} / \mathrm{kg}$ Körpergewicht i. v.) bzw. Tolbutamid (1 g i. v.). Differentialdiagnostisch muß bei Hypoglykämien auch an fortgeschrittene Leberleiden, Spätdumpingbeschwerden, Alkoholismus, sonstige Tumoren (Sarkome etc.) oder an medikamentös ausgelöste Erscheinungen („Hypoglycaemia factitia“) gedacht werden. Die Therapie erfolgt am besten durch die chirurgische Exzision des Tumors. Da es sich meist um kleine Bildungen handelt, ist eine präoperative Lokalisation durch selektive Angiographie, Computertomographie des Pankreas etc. oft nicht möglich. Hilfreich ist hier evtl. die transhepatische Katheterisierung der Pankreasvenen und gezielte Entnahme von Blutproben zur Insulinspiegelbestimmung. Andernfalls muß man versuchen, den Tumor während der Operation zu finden. Eine medikamentöse Therapie ist durch Diazoxid (100-300 mg/Tag) und durch Diphenylhydantoin zur Operationsvorbereitung bzw. bei inoperablen Fällen möglich; für die zytostatische Behandlung sind Streptozotocin und 5-Fluoruracil eingesetzt worden.

Einzelne Berichte liegen auch über Somatostatinome mit pathologischer Glukosetoleranz, Hypochlorhydrie und Maldigestion, Neurotensinome, pankreatisches Polypeptid sezernierende Geschwülste oder Enteroglukagonome vor. Es ist auszunehmen, daß in Zukunft weitere Tumoren identifiziert werden, die die ca. 30 derzeit diskutierten gastrointestinalen Hormone allein oder - häufiger - in der Kombination ausschütten.

Von multipler endokriner Adenomatose (MEA) spricht man, wenn verschiedene endokrin aktive Tumoren gleichzeitig wachsen. Beim Typ I werden die Kombinationen Hypophysentumor, Nebenschilddrüsentumor (bzw. Hyperplasie) und Inselzelltumor (Gastrinom, Insulinom, VIPom, Glukagonom, Karzi- 
noid) zusammengefaßt. Typ II ist die Kombination eines medullären Schilddrüsenkarzinoms und Phäochromozytoms; existieren daneben Anomalien (Marfan-Syndrom, Neurome) so wird diese Form als Typ III b bezeichnet. Bekannt wurden auch Mischtypen mit z. B. medullärem Schilddrüsenkarzinom und Inselzelltumoren. Jeder hormonbildende Tumor sollte mithin eine Suche nach weiteren ähnlichen Geschwülsten veranlassen. Da multiple endokrine Adenomatosen familiär gehäuft auftreten, müssen gegebenenfalls auch die Blutsverwandten untersucht werden.

\subsection{Diagnostik bei Verdacht auf eine Bauchspeicheldrïsen- erkrankung}

Jede unklare Beschwerde im Oberbauch sollte auch an eine Bauchspeicheldrüsenerkrankung denken lassen. Schmerzen werden zumeist gürtelförmig im linken, evtl. auch im rechten Oberbauch angegeben. Von der Nahrungsaufnahme werden sie gering beeinflußt. Ausstrahlungen werden in der linken Schulter bemerkt. Der Schmerzcharakter ist hell, schneidend. Oftmals werden durch eine vorgebeugte Körperhaltung, durch Eindrücken des Bauches mit den Armen bzw. durch die Anwendung von heißen Wickeln etc., die zu sichtbaren Pigmentierungen der Haut führen können, die Beschwerden gelindert. Weitere Zeichen können Übelkeit, Appetitlosigkeit, Erbrechen, Gelbsucht, massige Fettstühle, Gewichtsabnahme, Aszites sein.

Die körperliche Untersuchung trägt im Vergleich wenig bei; selten ist das Pankreas infolge einer Neubildung von Gewebe oder eine Zyste tastbar vergrößert. Hinweise können von einem nekrolytischen migratorischen Erythem auf ein Glukagonom, von Unterhautblutungen auf eine hämorrhagisch-nekrotisierende Pankreatitis und von einer Thrombophlebitis migrans auf ein Pankreaskarzinom ausgehen. Eine mäßige Vermehrung der Bauchdeckenspannung (,Gummibauch“) weist auf eine Irritation des Peritoneums, beispielsweise bei akuter Pankreatitis hin. Probleme entstehen vor allem bei den Fällen, in denen Schmerzen als führendes Symptom fehlen. In erster Linie handelt es sich um die Pankreasgeschwülste sowie um die zumeist schwergradig verlaufenden Entzündungen. Letztere zeigen sich dann z. B. durch Schock, Ileus oder akutes Nierenversagen bzw. nach langjährigem Verlauf durch eine exokrine Insuffizienz.

Während früher die Beurteilung der Bauchspeicheldrüse eine der schwierigsten Aufgaben war, kann diese heute durch die Hilfe der verbesserten klinischchemischen Tests und der verschiedenen bildgebenden Techniken leicht und routinemäßig erfolgen. Am Anfang empfiehlt sich folgendes orientierendes diagnostisches Programm, das rasch und einfach durchführbar ist und in vielen Fällen ausreichende Informationen erbringen kann:

1. Amylase, Lipase im Serum (s. 8.4); Blutsenkungsreaktion; rotes und weißes Blutbild; Serumparameter der Cholestase (Bilirubin, $\gamma$-Glutamyltranspeptidase, Transaminasen).

2. Amylase im Urin; Stuhlgewicht (an 3 aufeinanderfolgenden Tagen); Chymotrypsin im Stuhl. 
3. Sonogramm mit Darstellung der Bauchspeicheldrüse, Gallenblase, extraund ggf. intrahepatischen Gallenwege, Leber, Milz, Pfortaderzuflüssen. Ausschluß von Aszites.

Das Computertomogramm wird eingesetzt, wenn die Sonographie aus technischen Gründen oder aus anderen Überlegungen nicht ausreicht. Unklare Befunde können bei geringem Risiko sowohl unter sonographischer als auch unter computertomographischer Sicht mittels Feinnadeln punktiert werden, wobei Material für die histologische und zytologische Untersuchung gewonnen wird.

Ergeben sich aufgrund dieser „Basisuntersuchungen“ Hinweise für ein Pankreasleiden, so können zur Klärung weitere Tests gezielt eingesetzt werden:

1. Klinisch-chemische Parameter werden für die Klassifizierung der akuten Pankreatitis verwendet (s. Übersicht S. 479). Anhaltspunkte für ein Pankreasgeschwulst können die Serumkonzentrationen der Tumorantigene (CA 19-9, karzinoembryonales Antigen) oder Hormonspiegel (Gastrin, VIP, Glukagon, Insulin etc.) geben. Die Funktionsprüfungen des exokrinen Pankreas dienen der Diagnostik der chronischen Pankreatitis (s. 8.4).

2. Verkalkungen infolge chronischer Pankreatitis erkennt man auf einer Übersichtsröntgenaufnahme des Pankreas.

3. Die endoskopisch retrograde Cholangiopankreatographie (ERCP) wird für die Diagnostik und evtl. Therapie bei akuter biliärer Pankreatitis, bei chronischer Pankreatitis und beim Pankreaskarzinom eingesetzt.

4. Für die Tumordiagnostik können arterielle Pankreasgefäßdarstellungen oder transhepatische Katheterisierungen der Pankreasvenen zur gezielten Entnahme von Blutproben für Hormonbestimmungen dienen.

5. Selten werden die Laparoskopie und die diagnostische Peritonealspülung (bei akuter Pankreatitis) verwendet.

\section{Literatur}

1. Ammann RW, Akovbiantz A, Largiader F, Schueler G (1984) Course and outcome of chronic pancreatitis. Longitudinal study of a mixed medical-surgical series of 245 patients. Gastroenterology 86:820-828

2. Goebell H (1978) Was ist gesichert in der Therapie der akuten Pankreatitis? Internist 19:700

3. Gyr KE, Singer MV, Sarles H (1984) Pancreatitis. Concepts and classification. Excerpta Medica. Amsterdam, xxiii - xxv

4. Hansen W, Haberland H (1980) Vergleichende Untersuchungen zur Wertigkeit eines neuen Serumtrypsintests für die Diagnose der akuten Pankreatitis. Verhandl Dtsch Gesell Innere Med 86:1012-1013

5. Hollender LF, Lehnert P, Wanke M (1983) Akute Pankreatitis. Eine interdisziplinäre Synopsis. Urban \& Schwarzenberg, München, S 33

6. Klöppel G (1981) Endokrines Pankreas und Diabetes. In: Doerr W, Seifert G (Hrsg) (Spezielle pathologische Anatomie, Bd 14, S 648) Pathologie der endokrinen Organe. Springer, Berlin Heidelberg New York

7. Kuntzen O (1985) Exokrines Pankreas. In: Kaess H, Kuntzen O, Liersch M (Hrsg) Gastroenterologische Labordiagnostik. Springer, Berlin Heidelberg New York Tokyo, S $146-236$ 
8. Mayer AD, McMahon MJ, Corfield AP, Cooper MJ, Williamson RCIV, Dickson AP, Shearer MG, Imrie CW (1985) Controlled clinical trial of peritoneal lavage for the treatment of severe acute pancreatitis. N Engl J Med 312:399-404

9. Netter FH (1979) Digestive system. Part III Liver, biliary tract, pancreas, 2nd edn. CIBA Summit $\mathrm{p} 25$

10. Ranson JHC, Rifkind KM, Turner JW (1976) Prognostic signs and nonoperative peritoneal lavage in acute pancreatitis. Surg Gynecol Obstet 143:209-219

11. Sarles H (1984) Epidemiology and pathophysiology of chronic pancreatitis and the role of the pancreatic stone protein. Clin Gastroenterol 13:895-912 